\title{
Risk Aversion and Rights Accretion in Intellectual Property Law
}

\author{
James Gibson*
}

\begin{abstract}
Intellectual property's road to hell is paved with good intentions. Because liability is difficult to predict, intellectual property users often seek licenses even when proceeding without one might be permissible. Yet because the existence (vel non) of licensing markets plays a key role in determining the breadth of rights, these seemingly sensible licensing decisions eventually feed back into doctrine; the licensing itself becomes proof that the entitlement covers the use. Over time, then, public privilege recedes and rights expand, moving intellectual property's ubiquitous gray areas into what used to be virgin territory-where risk aversion again creates licensing markets, which cause further accretion of entitlements, which in turn push the gray areas even farther afield, and so on. This "doctrinal feedback" is not a result of changes in the positive law (the scholarship's usual focus), but is instead rooted in longstanding, widely accepted doctrine and prudent behavior on the part of everyone involved. Because feedback is so ingrained in established law and practice, its various cures tend to create more problems than they solve. There exists, however, one promising solution-subtle changes in doctrine's use of licensing information-that can keep intellectual property market-referential without making it market-reverential.
\end{abstract}

*. Director of the Intellectual Property Institute and Assistant Professor of Law, University of Richmond. E-mail: jgibson"richmond.edu. My thanks to Mark Lemley, Doug Lichtman, and the participants at the 2006 Stanford/Berkeley IP Scholars Conference for their helpful input. 


\section{Risk Aversion and Rights Accretion in Intellectual Property Law}

\section{TABLE OF CONTENTS}

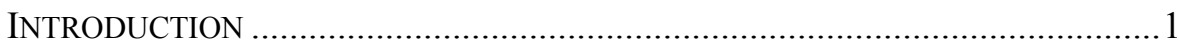

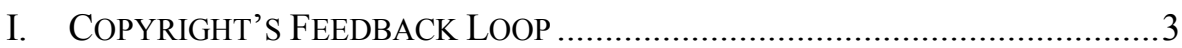

A. Doctrinal Indeterminacy and the Risk-Averse Actor ....................4

B. Market Circularity ............................................................... 10

C. Copyright's Doctrinal Feedback................................................12

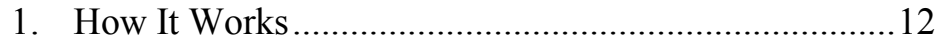

2. Positive Law and Strategic Behavior...........................14

3. Affected Markets............................................................16

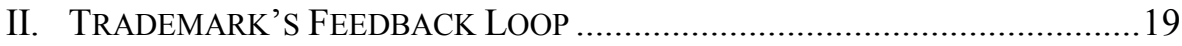

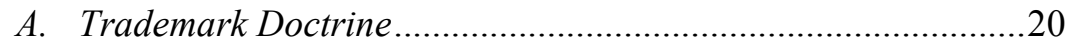

B. Licensing Motivations .........................................................24

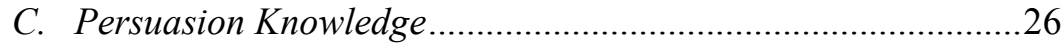

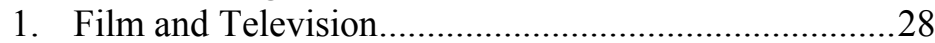

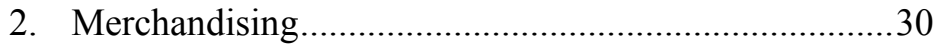

D. Limitations on Trademark's Feedback .......................................33

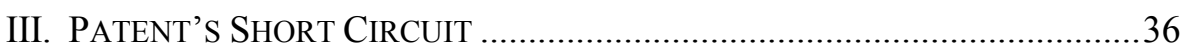

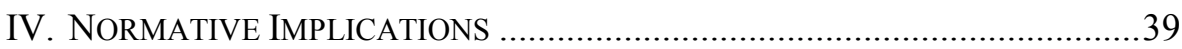

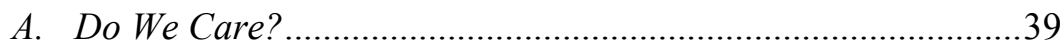

B. Reducing Uncertainty..............................................................42

1. Statutory Standards and Regulatory Rules ....................43

2. Increased Adjudication...............................................46

C. Reducing Consequences.......................................................48

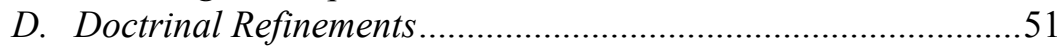

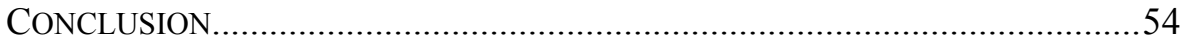




\title{
Risk Aversion and Rights Accretion in Intellectual Property Law
}

\section{INTRODUCTION}

\author{
Agree, for the Law is costly. -William Camden, $1605^{1}$
}

Intellectual property law is a growth industry. It covers an ever-expanding variety of subject matters, its protection lasts longer than ever, and its entitlements increasingly intrude into realms of conduct once reserved for public use. The blame (or, more rarely, credit) for this incessant growth usually falls on the agents of positive law-courts and legislatures-and the rent-seeking rightsholders who influence them.

But when it comes to one aspect of this expansion, the increasing breadth of intellectual property rights, much of the responsibility lies not with positive law's usual suspects, but with an organic, inadvertent process that results from the interaction of indeterminate doctrine and risk-averse licensing. Copyright law provides the best example. The copyright doctrines that determine where private entitlement ends and public privilege begins are inherently ambiguous. This means that those who want to make use of copyrighted material cannot make accurate ex ante judgments regarding the need to secure a license from the rightsholder. Yet making the wrong call can be costly, because the penalties for infringement typically include supracompensatory damages and injunctive relief. Combine these doctrinal gray areas and severe consequences with the risk aversion that pervades key copyright industries, and the result is a practice of securing copyright licenses even when none is needed. Better safe than sued.

In and of itself this state of affairs is unobjectionable, even laudable, in that the market provides certainty where the law does not. But licensing markets are not only the end result of legal doctrine; they are also instrumental in determining the reach of copyright entitlements. If a rightsholder can show that it routinely issues licenses for a given use, then copyright law views that use as properly falling within the rightsholder's control. Thus the practice of licensing within gray areas eventually makes those areas less gray, as the licensing itself becomes the proof that the entitlement covers the use. Over time, public privilege recedes and the reach of copyright expands, moving the ubiquitous gray areas farther into what used to be virgin territory, which in turn creates more licensing markets, which in turn push the gray area even farther afield, and so on. Lather, rinse, repeat.

This phenomenon, which I call "doctrinal feedback," is unappreciated in the intellectual property literature and unrecognized in the courts. Scholars and judges focus instead on top-down developments in the positive law-federal statutes, Supreme Court opinions, and so forth-never imagining that major transformations in the law could emerge from the bottom up, through practitioners' everyday application of longstanding, uncontroversial principles.

1. William Camden, Remains Concerning Britain 316 (EP Publishing 1974) (1605). 
For example, everyone agrees that certain copyright doctrines are ambiguous, and this ambiguity can be advantageous because it allows courts to reach equitable results despite substantial variation and complexity in the fact patterns they encounter. ${ }^{2}$ Everyone also agrees that licensing practice should play a key role in determining whether a given use falls within copyright's entitlement. Indeed, agreement on this issue unites otherwise disparate camps in copyright scholarship. ${ }^{3}$ Finally, everyone agrees that it is usually in a user's best interest to secure a license rather than take even a small risk of an adverse judgment; the simple reality is that finding out whether permission is required usually costs more than getting permission. But because these propositions are so uncontroversial, no one has noticed that their aggregate effect is an expansion in the reach of intellectual property rights-an expansion completely unconnected to lobbying successes and courtroom victories.

To be clear, I am not suggesting that intellectual property's growth is due entirely to seemingly sensible doctrines and prudent behavior on the part of everyone involved. Much of the recent expansion is obviously the result of purposeful policy decisions by courts and legislatures-and in certain areas such positivist decisions provide the entire explanation (e.g., expansions in the subject matter and duration of rights). But doctrinal feedback is its own animal, quietly contributing to the seemingly ceaseless growth of intellectual property, without relying on developments in legislation or litigation, on strategic behavior in the marketplace, or on rent-seeking initiatives by moneyed interests. In other words, even if intellectual property owners are guileless or have no interest in gaming the system, and even if statutes and case law are not overly favorable to rightsholders, the combination of ambiguous doctrine and riskaverse licensing will, over time, cause entitlements to grow and public privilege to shrink.

In this Article, I describe how doctrinal feedback works in intellectual property's three core disciplines and then address its normative implications. Part I looks at copyright law, where feedback's autocatalytic effect is particularly pronounced. It expands on the description given above, explores the sources of the risk aversion that produces so much unneeded licensing, and identifies those copyright uses and industries most likely to experience rights accretion.

Part II covers trademark law, where doctrinal feedback produces a less pervasive and more attenuated expansion, for two reasons. First, legal ambiguities and risk aversion are responsible for only some of trademark's superfluous licensing markets; others are the result of mutually beneficial promotional arrangements, such as product placement in film and television, which do not consistently feed back into the licensing calculus. Second, trademark law looks to consumer confusion, not licensing markets, when defining the reach of its entitlements, which means feedback occurs only when consumer perception reflects an acquired familiarity with licensing practices. I

2. See infra Part I.A.

3. See infra Part I.B. 
use research from the behavioral sciences-never before cited in the trademark literature-to show that consumers acquire this familiarity much more readily than trademark law acknowledges.

Part III discusses patent law, where doctrinal feedback, although present, is muted and produces no systemic expansion of entitlements. The difference is partly doctrinal (patent law does not use licensing information to define the overall reach of its entitlements) and partly purposeful (courts in patent cases are more skeptical of the informational content of licensing markets). Because patent law manages to make use of licensing information without suffering its distortive effects, however, it holds lessons for how we might address the more pernicious and expansive doctrinal feedback found in copyright and trademark.

I apply those lessons in Part IV, where I cease being descriptive and instead consider the normative implications of doctrinal feedback. The first normative question is whether doctrinal feedback is a problem. For those who generally oppose the expansion of intellectual property law, the answer is clearly yes-but I also show that those who favor an expansion should view doctrinal feedback as a poor means to that end. The next question is how one might solve the feedback problem. Reducing the risk aversion that fuels feedback is one obvious tactic, but that approach produces counterintuitive results laden with normative baggage, threatens to substitute a positivist expansion for an accretive one, and creates more problems than it cures. In the end, I suggest a more normatively neutral solution, consisting of subtle refinements in how the positive law scrutinizes licensing information and consumer motivation. This approach allows intellectual property to be market-referential without making it market-reverential.

\section{COPYRIGHT'S FEEDBACK LOOP}

Doctrinal feedback in copyright law arises from several uncontroversial premises. First, core doctrines-the idea/expression dichotomy, the substantial similarity test, and the fair use defense-create significant ambiguity regarding the reach of copyright rights. Second, new creative works almost invariably borrow from old creative works, which raises the possibility of infringement on the part of the borrower. Third, the penalties for copyright infringement are severe; monetary awards often vastly exceed what the defendant might have paid for a license, and injunctions are easy to come by. Fourth, the players in key copyright industries tend to be risk averse, a tendency exacerbated by high up-front investments and the need to satisfy conservative insurers and downstream distributors.

In combination, these factors cause copyright users to seeks licenses even when they have a good fair use claim-i.e, even when proceeding unlicensed would probably result in no liability. This practice of unneeded licensing feeds back into doctrine through one final uncontroversial premise: the fair use defense looks to the existence vel non of a licensing market when defining the reach of the copyright entitlement. The result is a steady, incremental, unintended expansion of copyright, caused by nothing more than ambiguous 
doctrine and prudent behavior on the part of copyright users.

\section{A. Doctrinal Indeterminacy and the Risk-Averse Actor}

Picture a filmmaker, camera in hand, interviewing passers-by on the streets of Cleveland for a documentary about the migration of American manufacturing jobs overseas. In one particularly poignant piece of footage, a homeless former factory worker spontaneously sings a lyric from a Bruce Springsteen song:

They're closing down the textile mill across the railroad tracks.

Foreman says these jobs are going, boys, and they ain't coming back. ${ }^{4}$

In post-production, as the filmmaker edits this clip into the documentary, she notices the singular features of Cleveland's Rock and Roll Hall of Fame looming in the background of the shot. The singing worker is also holding a copy of Newsweek, the cover of which is clearly visible. The thought crosses her mind: does she need permission to include the building in her film? The photograph on the magazine cover? For that matter, what about the two lines from the Springsteen song?

The prudent filmmaker would consult her lawyer, who would tell her that copyright law does indeed cover architectural, pictorial, and musical works, and that she may well have violated copyright's exclusive rights by including the building, photograph, and song excerpt in her film. ${ }^{5}$ On the bright side, her lawyer would probably also mention copyright's fair use defense and the protection it sometimes gives to defendants who make incidental and transformative use of copyrighted works.

But what would her lawyer's advice on fair use actually be?

This is an important question for our documentarian, because the fair use doctrine is the last exit off the highway to infringement. It is often the only thing standing between a litigant and liability. Fortunately, for those litigants who need it, the doctrine is endlessly malleable. It excuses a wide range of conduct, from parodying a pop song, ${ }^{6}$ to making personal copies of television programs for later viewing, ${ }^{7}$ to reverse-engineering a computer program for interoperability purposes. $^{8} \quad$ It can mutate into whatever form copyright's objectives demand. ${ }^{9}$

Fair use's adaptability, however, is a double-edged sword. Determining whether fair use excuses a defendant's conduct requires application of four

4. Bruce Springsteen, My Hometown, BORN IN THE U.S.A. (1983).

5. Whether the incidental inclusion of the building, cover, and song snippet is in fact a copyright violation is not entirely clear. See 4 Melville B. Nimmer \& DAVID Nimmer, COPYRIGHT, § 13.05[D][3]. As we will soon see, however, this lack of clarity is key to the phenomenon of doctrinal feedback.

6. Campbell v. Acuff-Rose Music, 510 U.S. 569 (1994).

7. Sony Corp. of Am. v. Universal City Studios, Inc., 464 U.S. 417 (1984).

8. Atari Games Corp. v. Nintendo of Am. Inc., 975 F.2d 832 (Fed. Cir. 1992).

9. Fair use "permits courts to avoid rigid application of the copyright statute when, on occasion, it would stifle the very creativity which that law is designed to foster." Stewart v. Abend, 495 U.S. 207, 236 (1990) (quoting Iowa State Univ. Research Found. v. Am. Broad. Cos., 621 F. 2d 57, 60 (2d Cir. 1980)). 
complicated, interdependent, and non-exclusive statutory factors ${ }^{10}$ and analysis of over 160 years of case law ${ }^{11}$-an intimidating and expensive undertaking. ${ }^{12}$ The case law has been particularly unhelpful. The Supreme Court's first incursions into fair use immediately struck a chord that still resonates in the jurisprudence: the doctrine's equitable, fact-specific, and thus indeterminate nature. $^{13}$ Those who were hoping for hard and fast rules were out of luck, and have remained so since. From the ex post perspective of the defendant already embroiled in the expense of litigation, then, an adaptable, equitable defense is useful. But for the prospective defendant wondering whether a given act will prove to be infringing, fair use is too ambiguous to provide much ex ante guidance. $^{14}$

This is not to say that our filmmaker has nothing on which to base a liability prediction. The 160 years of fair use case law have produced a number of decisions that address the incidental use of copyrighted materials in movies. Some of these cases support the filmmaker's fair use argument. ${ }^{15}$ Others do not. ${ }^{16}$ Presumably she and her lawyer could read the cases, extract those principles most relevant to her situation, and simply make a call.

In reality, however, they would do no such thing, because the risk is too

10. 17 U.S.C. $\$ 107$.

11. Although it did not actually use the term "fair use," Folsom v. Marsh, 9 F. Cas. 342, 344 (C.C.D. Mass. 1841), is commonly cited as the foundation of modern fair use analysis.

12. LAWrenCe LeSSig, Free Culture 187 (2004) (“[F]air use . . simply means the right to hire a lawyer to defend your right to create.”); Mark A. Lemley, Dealing with Overlapping Copyrights on the Internet, 22 U. DAYTON L. REv. 547, 566 (1997) (pointing out that "fair use ... is hard to predict in advance and that it will be expensive to prove"); Jessica Litman, Revising Copyright Law for the Information Age, 75 OREGON L. REv. 19, 45-46 (1996) ("[F]air use is a troublesome privilege because it requires a hideously expensive trial to prove that one's actions come within its shelter.").

13. Harper \& Row Publishers, Inc. v. Nation Enters., 471 U.S. 539, 552 (1985) (“"[F]air use analysis must always be tailored to the individual case."); Sony Corp. of America v. Universal City Studios, Inc., 464 U.S. 417, 448 \& n.31 (1984) (referring to fair use as an "equitable rule of reason" and citing with approval legislative history that asserts the impossibility of articulating a generally applicable definition). The Court's previous fair use cases had resulted in summary affirmance by an equally divided Court. Williams \& Wilkins Co. v. United States, 420 U.S. 376 (1975); Columbia Broadcast Sys. v. Loew’s, Inc., 356 U.S. 40 (1958).

14. The leading treatise underscores fair use's ambiguity, noting that the three major Supreme Court decisions on fair use "were overturned at each level of review, two of them by split opinions at the Supreme Court level." 4 NIMMER \& NIMMER, supra note 5, § 13.05. And it was the foundational fair use case, Folsom v. Marsh, that gave rise to Justice Story's famous statement that "[p]atents and copyrights approach, nearer than any other class of cases belonging to forensic discussions, to what may be called the metaphysics of the law, where the distinctions are, or at least may be, very subtle and refined, and, sometimes, almost evanescent." 9 F. Cas. at 344.

15. E.g., Jackson v. Warner Bros., Inc., 993 F. Supp. 585 (E.D. Mich. 1997); Monster Commc'ns, Inc. v. Turner Broad. Sys., Inc., 935 F. Supp. 490 (S.D.N.Y. 1996); Amsinck v. Columbia Pictures Indus., 862 F. Supp. 1044 (S.D.N.Y. 1994); Mura v. Columbia Broad. Sys., Inc., 245 F. Supp. 587 (S.D.N.Y. 1965).

16. E.g., Ringgold v. Black Entertainment Television, Inc., 126 F.3d 70 (2nd Cir. 1997); Brown v. McCormick, 23 F. Supp. 2d 594, 608 (D. Md. 1998). 
great. Not only is fair use famously ambiguous, but the price of making the wrong call is prohibitively high. Injunctions issue as a matter of course in copyright cases-and not just upon proof of liability: a copyright owner that proves likelihood of success on the merits presumptively wins a preliminary injunction without any need to show irreparable injury. ${ }^{17}$ If our filmmaker proceeds without a license, she faces the prospect of a lawsuit that could bring her production to a screeching halt and force her to negotiate permissions from those who hold her livelihood hostage, even if her fair use claim would ultimately prove meritorious. And if she loses the fair use argument, then she faces not only a permanent injunction, but a myriad of other sanctions-statutory damages, disgorgement of profits, attorney's fees-that may far exceed any license fee she would have had to pay. ${ }^{18}$

In these circumstances, even a risk-neutral actor with a good fair use claim would choose to secure a license rather than take the small risk of incurring a severe penalty. This is particularly so when the use of the copyrighted material, although incidental, is conspicuous. Take our filmmaker example: Newsweek is one of the country's most popular periodicals. The Rock and Roll Hall of Fame is instantly recognizable to anyone who has seen it. The Springsteen song was a top-ten hit. ${ }^{19}$ In all likelihood, then, unless her lack of liability is crystal-clear (and it rarely is, given the legal ambiguities), she will seek a license from all three potential plaintiffs before any of them so much as gets wind of her project.

This "license, don't litigate" tendency is compounded by two other factors. First, other key copyright doctrines share fair use's indeterminacy. For instance, copyright protects an author's individualized expression, but his or her more abstract ideas are free for the taking. ${ }^{20}$ Yet distinguishing between idea and expression is difficult; as Learned Hand once despaired, "Nobody has ever been able to fix that boundary, and nobody ever can." ${ }^{21}$ We find similar ambiguity in the "substantial similarity" standard by which courts evaluate how much copying is too much copying. ${ }^{22}$ Even if fair use were less imprecise, then, we would often be hard-pressed to determine exactly where private entitlement ends and public privilege begins.

Second, and more important, the decisionmakers in the real world of copyright practice are typically risk averse. New works of creativity often require high up-front investment, with the prospect of profit only after the work is completed. With so much at risk, those who work with copyrighted materials

17. Johnson Controls, Inc. v. Phoenix Control Sys., Inc., 886 F.2d 1173, 1174 (9th Cir. 1989); Apple Computer, Inc. v. Franklin Computer Corp., 714 F.2d 1240, 1254 (3d Cir. 1983); Atari, Inc. v. North Am. Philips Consumer Elecs. Corp., 672 F.2d 607, 620 (7th Cir. 1982); Wainwright Sec. Inc. v. Wall St. Transcript Corp., 558 F.2d 91, 94 (2d Cir. 1977).

18. 17 U.S.C. $\S \S 502$ (injunctions), 504 (damages and profits), 505 (attorney's fees).

19. The song hit number six on the Billboard Hot 100 in 1986.

20. 17 U.S.C. $\$ 102(b)$.

21. Nichols v. Universal Pictures Corp., 45 F.2d 119, 121 (2d Cir. 1930).

22. "The determination of the extent of similarity that will constitute a substantial, and hence infringing, similarity presents one of the most difficult questions in copyright law, and one that is the least susceptible of helpful generalizations." 4 NIMMER \& NIMMER, supra note 5, $\S 13.03[\mathrm{~A}]$ (footnote omitted). 
try hard to avoid potential pitfalls, and understandably so. They approach legal issues very conservatively, particularly issues like copyright liability, which have the potential to destroy or delay the entire project.

Examples abound. How-to books on copyright law-even those that do a good job explaining complex issues in plain English-tell readers to invoke fair use sparingly. "When in doubt, don't," they advise, ${ }^{23}$ heedless of the fact that doubt is copyright's constant companion. Publishers reduce the complexities of fair use to conservative bright-line rules that sacrifice accuracy for clarity: you may quote no more than $X$ number of words, or lines, or paragraphs. ${ }^{24}$ (The results sometimes border on the absurd, as when The New York Times seeks a license to excerpt four lines of poetry in a column that makes fun of publishers. ${ }^{25}$ ) The recording industry develops a practice of demanding and paying for licenses even when they are not needed. ${ }^{26}$ Even institutions of higher learning, which one would think have an interest in a more free-flowing information culture, implement overly restrictive and reductive fair use policies. ${ }^{27}$

These risk-averse tendencies are even more prominent among moneyed actors in mainstream industries like television and feature film, for two reasons.

23. Michael C. Donaldson, Clearance \& Copyright 67 (2d ed. 2003); accord StePhen Fishman, The Copyright Handbook: How To Protect \& Use Written Works 11/4 (7th ed. 2003); Richard Stim, Getting Permission: How To License \& Clear Copyrighted Materials Online \& OfF 9/5 (2000); Lloyd J. Jassin, Fair Use in a Nutshell: A Roadmap to Copyright's Most Important Exception, http://copylaw.com/new_articles/fairuse.html (last visited May 8, 2006).

24. "[A]lthough there is no legally established word limit for fair use, many publishers act as if there were one and require their authors to obtain permission to quote more then $[s i c]$ a specified number of words (ranging from 100 to 1,000 words)." FiSHMAN, supra note 23, at $11 / 8$. Despite his admonition, Fishman adds his own rule: "never quote more than a few successive paragraphs from a book or article, one or two lines from a poem, or take more than one graphic such as a chart, diagram or illustration." Id.; see also MARJORIE HEINS \& TRICIA BeCKles, Will Fair Use Survive? Free Expression in the Age of Copyright Control 15-16 (2005) (discussing specific numerical limits imposed by print publishers).

25. See Michael J. Madison, Legal-Ware: Contract and Copyright in the Digital Age, 67 FordHAM L. REV. 1025, 1077 (1998).

26. Matthew Africa, Comment, The Misuse of Licensing Evidence in Fair Use Analysis: New Technologies, New Markets, and the Courts, 88 CAL. L. REV. 1145, 1174-75 (2000).

27. One example, from the University of California:

It is important to understand that the law does not grant individuals the right to determine if they are making a fair use of a copyrighted work, rather, it provides guidelines for courts to make this decision on a case by case basis. Fair Use analysis is not simple and the outcome of a Fair Use defense is not predictable. It is unwise to assume that you are not infringing a copyright unless the specific use has been determined by case law to be non-infringing based on Fair Use, such as video taping television broadcasts for home use or copying a portion of a work to provided comment or criticism.

University of California, Office of the President, Office of Technology Transfer, Using Copyrighted Works of Others, http://www.ucop.edu/ott/crothers.html (2001); see also William W. Fisher III, Reconstructing the Fair Use Doctrine, 101 HARV. L. REV. 1659, 1694 (1988) ("[A]s almost any college teacher can attest, the information presently being given faculty by university counsel regarding how much copyrighted material they may reproduce for classroom use is distinctly unhelpful."). 
First, as the amount of money involved increases, so does the risk aversion. The more one has to lose-either in the form of initial investment or expected return-the more willing one is to incur marginal prophylactic expenses. Second, mainstream works intended for mass consumption have traditionally used a multi-tiered distribution model, in which a number of discrete parties need to be convinced that legal claims are unlikely. Even if our documentary filmmaker is willing to roll the dice on a fair use claim, she may need the backing of a major studio in order to get the movie made, and will almost certainly need a commercial distributor to get it into first-run theaters, pay-perview channels, the DVD market, and broadcast and cable television. Each of these stops along the distribution chain invites a new party to the table, and that party needs to be satisfied that the product it is peddling is not a time bomb of copyright liability. If the filmmaker is not inclined to be risk averse, then, one of these downstream players will be, and the end result will be the same. ${ }^{28}$ Thus one film that reportedly cost $\$ 218$ to make required an additional $\$ 230,000$ investment in licensing fees before a distributor was willing to take it on. ${ }^{29}$

In the movie industry, errors and omissions ("E\&O") insurance usually fulfills this need for a risk-averse approach. ${ }^{30}$ For a relatively small premium (less than $\$ 10,000$ for an independent film with no obvious legal problems), a filmmaker can obtain a policy that provides the protection necessary to placate the players at all levels. ${ }^{31}$ The premium, however, represents only part of the price. The typical E\&O insurance application not only presumes that the applicant has already paid an attorney to obtain clearances, but also requires the preparation of a copyright report setting forth a detailed history of the work and any related works. ${ }^{32}$ Written releases are necessary for all names, faces, and likenesses-even in fictional stories-and for any distinctive locations. "Film clips are dangerous," says the application, and their use requires licenses not just from the filmmaker, but from "all persons rendering services or supplying material contained in the film clip." ${ }^{34}$ Special attention must be paid to music, because of the hard-line position that music publishers take with regard to the

28. Keith Aoki, James Boyle \& Jennifer Jenkins, Bound By Law 53-54 (2006) (discussing effect on licensing when broadcasters and others mass distributors enter the picture); Patricia Aufderheide \& Peter Jaszi, Untold Stories: Creative Consequences of the Rights Clearance Culture fOR DOCUMENTARY FilmMAKers 5 (2005) ("Programmers, insurers and distributors are primarily concerned about legal risk to lawsuit, however frivolous ...."); HEINS \& BECKLES, supra note 24, at 55 (noting that "gatekeeper-intermediaries-publishers, broadcasters, distributors, and many ISPs- . . . care less about legal niceties or the rights of users than about avoiding expensive lawsuits.").

29. Nancy Ramsey, The Hidden Cost of Documentaries, N.Y. TIMES, Oct. 16, 2005, §2, at 13 (discussing the film Tarnation).

30. AUFDERHEIDE \& JASZI, supra note 28, at 9 (calling E\&O insurance the "chokepoint" of rights).

31. DonALDSON, supra note 23, at 199.

32. Id. at $47,203,211,214$.

33. Id. at 214. Obviously some of these requirements speak to claims under something other than copyright law, such as trademark and right of publicity.

34. Id. at 215. 
need for new licenses for each reuse. ${ }^{35}$ Any failed attempt to secure a release must be reported on the application. ${ }^{36}$ And woe betide him who fails to fulfill the insurer's demands that everything be licensed; filing a claim on an E\&O policy can be the death knell for any future project. ${ }^{37}$

My purpose here is not to indict insurers. They are simply facilitating the risk aversion of the other players in the industry. And those who wish to avoid this licensing morass can choose not to include in their films anything drawn from existing material, or can assume the risk themselves by using nontraditional distribution methods like the Internet or other self-publishing. ${ }^{38}$

But the E\&O insurance application casts one important point in stark relief: being held liable is a secondary concern. It's being sued at all that poses the greater threat. The applicant must report any intellectual-property-related claims brought against him or her in the last five years, whether successful or not, plus any prospect of claims relating to the current project and any facts under which a claim "might reasonably be asserted or legal proceeding instituted." 39 Any matter "potentially actionable" must be removed from the script. ${ }^{40}$ And the application closes with a general admonition to focus not on the merits of a potential claim, but on "the likelihood of any claim or litigation." 41 Again, better safe than sued.

From the perspective of the risk-averse actor, this makes sense. The ready availability of a preliminary injunction that can stop a production in midstream is enough to strike fear in the heart of any investor, not to mention the distraction and expense of defending against a lawsuit. Transactional attorneys are accordingly paid not to avoid liability, but to avoid litigation. And when they combine their clients' understandable risk aversion with the ambiguity of the applicable legal doctrines, they are to be praised, not blamed, for advising the negotiation of licenses. ${ }^{42}$ As one how-to book sagely states, "An unfinished project, no matter how brilliantly conceived, is preferable to a lawsuit for copyright infringement any day." ${ }^{43}$

35. Id

36. Id. at 211.

37. "If you ever have a claim on E\&O insurance, you might as well go into another line of work. You can never file a claim or you get blacklisted-and never be insured again." AUFDERHEIDE \& JASZI, supra note 28, at 23 (quoting historical filmmaker Robert Stone).

38. "At one extreme is the film world, where a clearance culture and the need for E\&O insurance have nearly obliterated fair use. At the other end of the spectrum are the students, Web activists, and artists who freely appropriate copyrighted or trademarked material for creative purposes." HeINS \& BECKLES, supra note 24, at 54.

39. DONALDSON, supra note 23, at 212.

40. Id. at 214 .

41. Id. at 215 .

42. Fisher, supra note 27 , at 1693 ("The most telling indication of the seriousness of [the indeterminacy of fair use] is the character of the advice currently being given the members of those groups by their lawyers.").

43. Lee Wilson, Fair Use, Free Use, And Use by Permission 153 (2005). Wilson also provides a related example of wise (if dismaying) advice:

Never decide to use a copyrighted work after you have been denied permission to do

so. Your transgression will be no greater than it would have been had you never 
Small wonder, then, that two recent studies-one that focused on documentary filmmakers, the other on the larger creative community-found that overly conservative licensing practices predominate even in the face of good fair use claims, resulting in a licensing culture that significantly and negatively impacts the creation of valuable new works. ${ }^{44}$ In the end, copyright's substantive law matters very little, except in its ambiguity. ${ }^{45}$

\section{B. Market Circularity}

We now see that risk-averse actors in important copyright industries tend to seek copyright licenses when they don't need to. That's the first piece of the doctrinal feedback puzzle. The second piece is equally uncontroversial, viz.: fair use doctrine places substantial weight on existing licensing practices. In other words, when a court is determining whether a given use of copyrighted material is fair, one important factor is whether there already exists a licensing market for the use in question. If such a market does not exist, then the fair use claim gains ground. If the market does exist, then the fair use claim loses ground. I call this puzzle piece uncontroversial because the link between licensing practice and fair use doctrine is widely accepted not only by the courts, but also by a varied collection of scholars who hold otherwise divergent views on fair use.

First, the courts. The statutory definition of fair use sets forth four factors for judges to consider in deciding whether a given use is fair. ${ }^{46}$ Although they remain free to consider other factors as well, the four that the statute explicitly lists tend to dominate the jurisprudence. ${ }^{47}$ And the Supreme Court, the lower courts, and commentators have all recognized that of the four, it is the last factor-"the effect of the use upon the potential market for or value of the copyrighted work"- that is the most important. ${ }^{48}$

Within this "market effect" factor, however, lies the danger of circularity, in

requested such permission, but your action in defiance of the denial of permission to use the work is likely to anger the owner of the copyright. Anger is an important ingredient in lawsuits.

$I d$. at 152 . Such is the power that risk aversion puts in the hands of copyright owners. Creators of new works are advised to seek permission when in doubt as the legality of their activity (and such doubt almost always exists), and when that permission is refused they are advised not to take the chance that it was not needed in the first place.

44. AUFDERHEIDE \& JASZI, supra note 28; HEINS \& BECKLES, supra note 24.

45. "The rules that publishers impose upon writers, the rules that film distributors impose upon filmmakers, the rules that newspapers impose upon journalists-there are the real laws governing creativity." LESSIG, supra note 12, at 187.

46. 17 U.S.C. $\$ 107$.

47. See, e.g., Triangle Publ'ns, Inc. v. Knight-Ridder Newspapers, Inc., 626 F.2d 1171, 1175 n.10 (5th Cir. 1980).

48. E.g., Harper \& Row Publishers, Inc. v. Nation Enters., 471 U.S. 539, 566 (1985); Princeton Univ. Press v. Mich. Document Servs., Inc., 99 F.3d 1381, 1385 (6th Cir. 1996); Triangle Publ'ns, 626 F.2d at 1175; see also 4 NiMMER \& NiMMER, supra note 5, § 13.05[A][4] ("If one looks to the fair use cases, if not always to their stated rationale, this emerges as the most important, and indeed, central fair use factor.") (footnotes omitted). 
which market effect plays the part of both premise and conclusion. Whether a given use affects a work's market depends on whether the copyright owner has the legal authority to exact payment for that use. And it is that legal authority that is the ultimate question to be answered in fair use analysis. In other words, we cannot know the market effect until we first decide whether there is a market to be affected-yet market effect is supposed to help us make that decision.

Some courts recognize the tautologic potential here. ${ }^{49}$ Their usual response is to try to break the vicious circle by disregarding purely theoretical revenue streams, focusing instead on "those that creators of original works would in general develop or license others to develop" reasonable, or likely to be developed." ${ }^{51}$ When the defendant's use has only recently become possible (e.g., because it uses a new technology), these standards may do little to clear the muddy waters of circularity; who can say whether an unforeseen use is "reasonable" or is "likely to be developed" by the copyright owner? But when the use is one that has been around long enough for a licensing market to develop, the presence or absence of such a market goes a long way toward deciding the case. ${ }^{52}$ In effect, then, fair use jurisprudence in established industries depends a great deal on customary practice.

The fair use scholarship ends up in much the same place, albeit sometimes by a different route. Scholarly references to customary licensing practices as a fair use factor go back some ninety years (making them even older than court references), ${ }^{53}$ but licensing markets are perhaps most significant to those modern-day scholars who view fair use as an agent of economic efficiency. Their argument is straightforward: fair use exists to ensure that welfareenhancing uses of copyrighted material will take place even when transaction costs impede consensual market transfers of copyright permissions. ${ }^{54}$ It follows that when established practice shows that consensual transfer is possible-i.e., when the particular use is in fact consistently licensed-the fair use defense is

49. E.g., Princeton Univ. Press, 99 F.3d at 1387; Am. Geophysical Union v. Texaco Inc., 60 F.3d 913, 929 (2d Cir. 1994). Other courts don't recognize the danger of circularity. E.g., Wall Data Inc. v. Los Angeles County Sheriff's Dep't, 447 F.3d 769, 781 (9th Cir. 2006) ("Whenever a user puts copyrighted software to uses beyond the uses it bargained for, it affects the legitimate market for the product.").

50. Campbell v. Acuff-Rose Music, Inc., 510 U.S. 569, 592 (1994).

51. Am. Geophysical, 60 F.3d at 930.

52. E.g., Harper \& Row Publishers, Inc. v. Nation Enters., 471 U.S. 539, 567-69 (1985); Princeton Univ. Press, 99 F.3d at 1387; Shapiro, Bernstein \& Co. v. P. F. Collier \& Son Co., 26 U.S.P.Q. 40, 42 (S.D.N.Y. 1934).

53. E.g., ARthur W. Weil, American Copyright LaW 429 (1917); Richard C. De Wolf, AN OutLine OF COPYRIGHT LAW 143 (1925); Elizabeth Filcher Miller, Note, Copyrights - "Fair Use," 15 S. CAL. L. ReV. 249, 250 (1942); Saul Cohen, Fair Use in the Law of Copyright, 6 COPYRIGHT L. SYMP. (ASCAP) 43, 51-52 (1955). The oldest judicial use of licensing practices-or, more accurately, the lack thereof-in a fair use case is in Shapiro, Bernstein \& Co., 26 U.S.P.Q. at 42.

54. The foundational article is Wendy J. Gordon, Fair Use as Market Failure: A Structural and Economic Analysis of the Betamax Case and Its Predecessors, 82 CoLuM. L. ReV. 1600 (1982). 
unavailable. $^{55}$

Curiously, scholars who reject this economic approach nevertheless come to the same conclusion. ${ }^{56}$ For example, Lloyd Weinreb argues that customary practice should heavily influence fair use determinations, not because it is a proxy for economic efficiency, but because fair use embodies notions of fundamental fairness that transcend narrow consideration of copyright's utilitarian underpinnings. ${ }^{57}$ Gideon Parchomovsky views fair use through a Kantian lens of individual rights and autonomy, yet he too concludes that "only users whose takings comport with customary practices that govern creative activities in the relevant community should be able to avail themselves of the fair use doctrine." ${ }^{, 58}$ And Michael Madison's "pattern-oriented" approach to fair use asks "whether an individual's use of a work without the consent of the copyright owner is consistent with a provable social or cultural pattern of conduct." $" 59$

Scholars of all stripes thus agree with the courts: the existence vel non of traditional licensing markets should play an important role in determining whether fair use protects an unauthorized use of copyrighted material. As we will now see, however, when we combine this perfectly reasonable consideration with the perfectly reasonable, risk-averse, "license, don't litigate" attitude that prevails in important copyright industries, something strange happens. I call it "doctrinal feedback," and it is the source of inadvertent expansion in the reach of copyright entitlements.

\section{Copyright's Doctrinal Feedback}

\section{How It Works}

Doctrinal feedback works like this. In Year One, $X$ wants to incorporate part of $Y$ 's copyrighted work into $X$ 's project. Assume $X$ 's use is transformative and involves a quantitatively and qualitatively small portion of published material. In other words, under the first three statutory factors, it's a decent fair use candidate. ${ }^{60}$ As for the fourth factor, there is no established licensing

55. Id. at 1613, 1615; Fisher, supra note 27 , at 1727-29.

56. Wendy Gordon is now arguably one such scholar, her views on fair use having evolved since her 1982 article. She now sees the market as an imperfect measure of the values that the doctrine represents. See Wendy J. Gordon, Excuse and Justification in the Law of Fair Use: Commodification and Market Perspectives, in The CoMmodificATION OF INFORMATION 149 (Niva Elkin-Koren and Neil Weinstock Netanel eds. 2002). Yet despite her apostasy, she still concludes-if for somewhat different reasons-that established licensing practice should be a major factor in fair use analysis. See Wendy J. Gordon, Render Copyright Unto Caesar, 71 U. CHI. L. REV. 75, 90 (2004).

57. Lloyd L. Weinreb, Fair's Fair: A Comment on the Fair Use Doctrine, 103 HaRV. L. REV. 1137, 1159-61 (1990).

58. Gideon Parchomovsky, Fair Use, Efficiency, and Corrective Justice, 3 LEGAL THEORY 347, 349 (1997).

59. Michael J. Madison, A Pattern-Oriented Approach to Fair Use, 45 WM. \& MARY L. REV. 1525, 1530 (2004).

60. See Harper \& Row Publishers, Inc. v. Nation Enters., 471 U.S. 539, 552-53, 564-65 
market for $X$ 's use. So $X$ figures that he has a good shot-let's say $80 \%$-at a fair use defense. But that still leaves a $20 \%$ chance the use might be ruled infringing. $X$, being risk averse and aware of the severe consequences of an adverse ruling, decides not to take that chance and so seeks and pays for a license from $Y$ instead.

Over time, other similarly situated parties follow suit. By Year Three, then, there has emerged a widespread, active licensing market for the kind of use in which $X$ engaged. This means that in Year Four, the chances of winning a fair use argument for $X$ 's kind of use have dropped considerably, because the existence of the licensing market militates against a fair use finding. Now the use that was $80 / 20$ in favor of fair use is more like 20/80 against. The riskaverse preference for licensing has circled back around into the doctrinal analysis and the reach of $Y$ 's copyright has expanded. This expanded reach also means that related uses of $Y$ 's work that once would have been considered even more safe than $X$ 's will start to become more risky, because the newly expanded licensing market affects the analysis in related markets as well.

On the one hand, then, we have legal standards that quite reasonably look to the existence of a licensing market when defining the breadth of fair use. On the other, we have an equally reasonable and possibly laudable tendency to obtain licenses where none may be needed. Over time, fair use naturally shrinks and the scope of copyright expands. Rather than disappearing, copyright's gray areas move farther into conduct that used to be reserved for public use. This movement creates more licensing markets, which in turn push the gray area even farther afield, and so forth.

What about those who resist the pressure to license-the risk-takers who use copyrighted material without authorization? Unfortunately, such mavericks do little to stave off doctrinal feedback. For one thing, they are likely to be few and far between, for reasons already explained, and will thus play no significant part in determining the licensing culture. And even if they exist in greater-thanexpected numbers, their influence on licensing norms will be disproportionately small, for two reasons. First, risk takers may rely on fair use, but that doesn't mean they want to have to prove their case in court. They will accordingly try to keep their unlicensed conduct quiet. ${ }^{61}$ In contrast, copyright owners have every reason to flaunt each license they secure. Second, because risk aversion increases as projects get more expensive and mainstream, most risk takers will come from smaller-scale projects that do not involve widespread distribution through traditional channels. Unauthorized uses will therefore receive disproportionately little attention when courts and practitioners evaluate

(1985) (holding that published works are better fair use candidates than unpublished works and examining both quantitative and qualitative volume of copying); Campbell v. Acuff-Rose Music, 510 U.S. 569, 578-79 (1994) (holding that fair use favors transformative uses).

61. The exception that proves the rule is the defendant in Princeton University Press v. Michigan Document Services, Inc., 99 F.3d 1381, 1384 (6th Cir. 1996), who was "something of a crusader against the system under which his competitors ha[d] been paying agreed royalties"-and who paid the price when the court rejected his fair use claim. 
licensing practices. $^{62}$

Foreign law constitutes one final distortive influence here. To the extent that a film, book, song, etc. is intended for international distribution, the author must worry about foreign intellectual property regimes, which can be more restrictive than domestic law when it comes to unlicensed use of existing works. $^{63}$ The prevailing licensing practice in the U.S. might therefore reflect these foreign restrictions, and courts and practitioners unwittingly invite those restrictions into U.S. law by relying on that licensing market in domestic fair use analysis.

\section{Positive Law and Strategic Behavior}

One of the interesting things about the doctrinal feedback phenomenon is that it works an expansion of the copyright entitlement in an inadvertent, accretive manner. The whole idea is that risk-averse behavior prevents fair use claims from being litigated, so a licensing culture emerges based on very few and very infrequent guidelines from the positive law. Instead of looking to courts and statutes for guidance, practitioners look to the internal practices of the relevant industries, and then apply the same market-referential standards that they would expect courts to apply if they were ever to litigate.

This means that those typically blamed for copyright's growth-courts and legislatures-play at best a secondary role in this insidious means of expansion. Doctrinal feedback has little to do with case law and statutes, except insofar as reported decisions entrench the statutory ambiguities that give rise to the risk aversion in the first place. It is an independent phenomenon that works its expansion regardless of whether courts and legislatures favor that outcome and regardless of whether copyright owners engage in rent-seeking behavior. Even if copyright owners were guileless or had no interest in gaming the system, and even if statutes and case law were not overly favorable to rightsholders, the combination of ambiguous doctrine and risk-averse tendencies would result in an accretion of rights.

That said, strategic behavior on the part of copyright owners can certainly exacerbate the accretive effect of doctrinal feedback. Indeed, the only two commentators who have previously noticed this aspect of copyright circularity have ascribed the phenomenon not to structural causes, as I do, but to purposeful conduct on the part of entitlement holders. ${ }^{64}$ Such strategic behavior

62. Many who rely on fair use "are afraid to admit to doing so publicly, for fear of drawing attention and legal action, whether frivolous or not-thus robbing the recourse of fair use from public precedent." AUFDERHEIDE \& JASZI, supra note 28, at 29-30.

63. For example, France allows no unauthorized use of unpublished works and provides no catch-all fair use defense even for unpublished works. J.A.L. STERLING, WORLD COPYRIGHT LAW 345, 447 (2d ed. 2003).

64. Lydia Pallas Loren, Redefining the Market Failure Approach to Fair Use in an Era of Copyright Permission Systems, 5 J. INTELL. PROP. L. 1, 41 (1997) (ascribing growth of licensing market to self-serving strategic agreements among repeat players); Africa, supra note 26, at 1166 ("Strategic behavior by users has not only prevented the creation of fair standards, it has entrenched unfair ones."). 
is not a necessary condition for doctrinal feedback, but if we relax the assumption that everyone involved is ingenuous, we see that the feedback effect is in fact highly manipulable. For example, the ubiquitous cease-and-desist letter might represent rightsholders' attempt to change the risk calculus in their favor, because such a letter (whether threatening or conciliatory) tells the recipient that the rightsholder knows of the use. ${ }^{65}$ Even when the argument for liability is weak, the letter's recipient knows that he or she can no longer hope to proceed unnoticed.

Another way in which copyright owners might game the system is by engaging in a sort of mutual backscratching: I'll license your works if you license mine. Both Lydia Pallas Loren and Matthew Africa have observed that a large publishing or media company is as likely to be licensor as licensee, because of its extensive collections of copyrighted works. Such repeat players may therefore not fear a licensing culture, under the theory that the payments they make and the payments they receive will net out. ${ }^{66}$

Yet if this sort of strategic backscratching is indeed a zero-sum game, one might wonder why repeat players would purposely choose to encourage licensing and its associated transaction costs rather than the alternative culture of comparatively costless fair use. Indeed, Gideon Parchomovsky has suggested that as a normative matter copyright should allow permissionless intra-industry appropriation-i.e., members of a common authorial community should be able to claim fair use of each other's material because they share a reciprocal risk of being infringed, which makes the intrusion on their property right in copyright morally acceptable. ${ }^{67}$ As a descriptive matter, however, the publishing industry apparently does just the opposite, as does the recording industry. ${ }^{68}$

Moreover, it is not clear that strategic behavior predominates, or even that copyright owners understand the rent-seeking opportunities that doctrinal feedback presents. The copyright literature is full of examples of rightsholders who demand exorbitant fees for incidental uses from parties who cannot afford them. ${ }^{69}$ If true, such examples suggest that copyright owners are not gaming the system, or at least not in a way that consistently serves their self-interest, because it is almost always in a rightsholder's interest to agree to license an arguably fair use, so as to create a market that can later be used to argue that the

65. See HeIns \& BECKLES, supra note 24, at 29-37; Africa, at 1172.

66. Loren, supra note 64, at 41; Africa, supra note 26, at 1172 . This argument has surfaced in patent disputes as well. E.g., EWP Corp. v. Reliance Universal Inc., 755 F.2d 898, 907-08 (Fed. Cir. 1985).

67. Parchomovsky, supra note 58, at 370-71.

68. Loren, supra note 64, at 41; Africa, supra note 26, at 1174 . Perhaps the explanation is that non-economic considerations, such as a sense of moral desert, play a role in the formation of licensing practices. More likely, however, is that licensing markets that form within a given group are not entirely internal, but instead can be used to rebut a fair use argument made by someone external to the industry. See Loren, supra note 64, at 41-43.

69. E.g., AUFDERHEIDE \& JASZI, supra note 28, at 12-19; HEINS \& BECKLES, supra note 24, at 19; LESSIG, supra note 12, at 95-97; see also AUFDERHEIDE \& JASZI, supra note 28, at 12-13 (describing "most favored nation" clauses that require licensees to pay all rightsholders the highest fee that it negotiates with any of them). 
use is not in fact fair. ${ }^{70}$ The only reason to refuse to license in such circumstances is to engage in brand management (i.e., the use imposes unacceptable congestion costs or tarnishes the work $)^{71}$ or to send an inflationary price signal (i.e., prospective licensees need to know that the rightsholder cannot always be bargained down). Even then, granting a license remains an attractive option unless the licensing market is already so well established that the likelihood of a successful fair use claim has become negligible.

On the opposite side of the transaction, copyright users may or may not be aware of doctrinal feedback and its consequences, but here too the feedback will occur regardless of the participants' awareness. Yet unlike copyright owners, copyright users will find it hard to manipulate doctrinal feedback to their advantage once they become aware of it, because they face a collective action problem: if one of them resists licensing but the rest do not, the resistor is facing a tougher fair use argument. ${ }^{72}$ Even if users realize that they are digging their own grave every time they agree to a license, then, resistance only helps if a critical mass of users resist. This is a classic prisoner's dilemma, and overcoming the dilemma's usual barriers to trust and coordination is difficult, particularly when the insurers come calling. Besides, copyright users may not be getting fully disinterested advice. Once we relax our assumption of ingenuousness, we must realize that the lawyers who counsel clients on the need to license have a strategic interest too: advising clients to seek a license creates more earning opportunities for transactional attorneys than does advising them to roll the dice on a fair use claim.

\section{Affected Markets}

Where might we expect doctrinal feedback to be the most pronounced? The answer to this question depends on a number of factors. In descending order of importance, they are: the parties involved, the content being used, the mens rea of the user, and the uniformity of the legal precedent.

As already discussed, where moneyed actors predominate, where multiple parties must sign off on the use, and where up-front costs are highest, increased risk aversion and a strong feedback effect are most likely. Thus reliance of fair use will probably be the least frequent and the least well received in the feature

70. See Loren, supra note 64, at 42-43.

71. See Laura Bradford, Parody and Perception: Using Cognitive Research To Expand Fair Use in Copyright, 46 B.C. L. REV. 705 (2005) (describing approach to fair use based on preserving value of work); see also James Gibson, Once and Future Copyright, 81 NoTRE DAME L. REV. 167, 216-20 (2005) (discussing copyright as vehicle for censorship rather than exploitation of work).

72. See Princeton University Press v. Michigan Document Services, Inc., 99 F.3d 1381 (6th Cir. 1996) (finding no fair use on part of one copy shop that resisted licensing arrangements to which its competitors had agreed). One resistance tactic less vulnerable to the prisoner's dilemma problem would be for users to insist on "escape clauses" in their licensing agreements, under which they explicitly deny the legal necessity for the license even as they agree to it. This approach has enjoyed some success in the patent context. Burgess Cellulose Co. v. Wood Flong Corp., 431 F.2d 505, 510 (2d Cir. 1970). 
film industry, with its high initial investments, availability of funds for licenses, and tiered distribution system. Indeed, one recent study concluded that "a clearance culture and the need for E\&O insurance have nearly obliterated fair use" in the film world. ${ }^{73}$ We find some of the same characteristics in the traditional music, broadcasting, advertising, and publishing industries. Together these represent almost all of copyright's most significant markets. ${ }^{74}$ In contrast, starving artists who rely on online distribution and other affordable, neoteric channels of trade are least likely to suffer a feedback effect, ${ }^{75}$ and private fair uses like the time-shifting in the well-known Betamax case will likewise be relatively unaffected. ${ }^{76}$

The nature of the content taken from the copyright owner also affects the risk calculus: the more detectable the appropriation, the more likely the license. Literal copying-e.g., taking footage from a movie-will be the most apparent to the investors, insurers, and potential plaintiffs from whom pressure to license emanates. It is easy for the money man to notice that the film he is underwriting uses a clip from The Godfather, and thus to demand that the use be licensed. It is not as easy for him to notice that the film borrows a plot device from The Godfather. ${ }^{77}$ Thus uses involving "fragmented literal similarity," ${ }^{, 78}$ where the second work incorporates discrete snippets of expression directly copied from the first work (a few seconds of film footage, a few bars of a song, a few lines of a poem), are most likely to lead to doctrinal feedback. This has particular significance in our modern "remix culture," in which recombination of old expression is an increasingly essential step in the creation of new works. ${ }^{79}$

To a lesser extent, the awareness of the borrower that something has been borrowed will affect whether a licensing culture develops. The user of copyrighted material will only consider seeking a license when he or she realizes that such a use has taken place; when the use is accidental and incidental rather than purposeful, the prospect of seeking a license might never even occur to the user. Ignorance, however, is not bliss: this scenario is unlikely to play much of a role in retarding the accretive expansion of the copyright entitlement because it is unlikely that many users will be ignorant or will maintain their ignorance as their work moves from creation to distribution. ${ }^{80}$ Those who earn a living from

73. HEINS \& BECKLES, supra note 24 , at 54.

74. The lone exception is probably software. See StePhEn E. SiweK, Copyright INDUSTRIES IN THE U.S. ECONOMY 18 (2004) (describing copyright's core industries).

75. HEINS \& BECKLES, supra note 24, at 54.

76. Sony Corp. of Am. v. Universal City Studios, Inc., 464 U.S. 417, 447-55 (1984) (holding that recording television programs for later viewing on Betamax was fair use).

77. Furthermore, more abstract and obscure takings may not need to rely on fair use; the idea/expression dichotomy and de minimis defense will provide some cover. If so, feedback is even less likely, because (unlike fair use) the application of the idea/expression dichotomy and the de minimis defense does not depend on the existence of a licensing market.

78. This term is from the Nimmer treatise. See 4 NimMER \& NimMER, supra note 5, $\S 13.03[\mathrm{~A}][2]$.

79. See Justin Hughes, Size Matters (or Should) in Copyright Law, 74 FordHAm L. ReV. 575, 578-79 (2005) (discussing prevalence and importance of "remix culture").

80. I am speaking descriptively here. As a normative matter, incidental and accidental uses might be better fair use candidates than purposeful uses (all else being equal), because when the 
working with copyrighted materials tend to be sensitive to the licensing issue. ${ }^{81}$ Moreover, in those industries where several different players must sign off on a given work, someone in the distribution chain is bound to notice the incorporation of copyrighted material, particularly when it is of the "fragmented literal similarity" kind. And both ignorance and bliss will disappear entirely if, upon the work's release, the copyright owner notices the use and sends the user a cease-and-desist letter or files suit. At that point, the user must confront the same "license or litigate" question that he or she had theretofore unwittingly managed to avoid.

Finally, even the risk-averse will presumably not seek a license in the face of clear legal precedent that obviates the need to do so. Such uses will thus not be vulnerable to the feedback effect. Unfortunately, there are few areas in which the case law provides clear precedent. Even in the case most favorable to creators who reuse copyrighted material, the Supreme Court remanded for further consideration of licensing evidence, ${ }^{82}$ and the Court has been adamant in its view that each case is unique and fact-dependent. ${ }^{83}$ Nor has the Court ever clarified the other ambiguous doctrines in feedback's causal chain (the idea/expression dichotomy and the substantial similarity test). ${ }^{84}$ Case law from the lower courts is, not surprisingly, both more developed and more diverse. For every case that finds an incidental background use fair, there is another that does not. ${ }^{85}$ When the defendant manages to prevail, the holding sometimes reflects not an informed approach to licensing evidence, but a failure to consider it at all. ${ }^{86}$ And when we bring foreign law into the picture-a necessary

defendant has purposely chosen to incorporate the plaintiff's work, there's a better argument that there was something about the work that the defendant values and should pay for. $C f$. Africa, supra note 26, at 1175 (viewing unknowing incidental use as "perhaps [the] most troubling" aspect of feedback effect).

81. See generally AUFDERHEIDE \& JASZI, supra note 28 (demonstrating awareness of licensing issue among independent documentary filmmakers).

82. See Campbell v. Acuff-Rose Music, 510 U.S. 569 , 593-94 (1994).

83. Harper \& Row Publishers, Inc. v. Nation Enters., 471 U.S. 539, 552 (1985) (“" $\mathrm{F}]$ air use analysis must always be tailored to the individual case."); Sony Corp. of America v. Universal City Studios, Inc., 464 U.S. 417, 448 \& n.31 (1984) (referring to fair use as an "equitable rule of reason" and citing with approval legislative history that asserts the impossibility of articulating a generally applicable definition).

84. See 4 Nimmer \& Nimmer, supra note 5, § 13.03[E][1][b] ("In recent decades, the Supreme Court has confronted numerous copyright issues; yet none of those cases posed the line-drawing issue of how far a defendant can go without committing prima facie infringement."). The only case in which the Court can be said to have focused on the distinction between idea and expression was Baker v. Selden, 101 U.S. 99 (1879), which because of its age and the nature of the materials involved (accounting books and charts) does little to clear up the larger idea/expression ambiguity, giving rise instead to the narrower merger doctrine.

85. E.g., compare Shapiro, Bernstein \& Co., v. P. F. Collier \& Son Co., 26 U.S.P.Q. 40 (S.D.N.Y. 1934) (conjecturing that "the instance of a person being photographed incidentally reading a current magazine in which the copyrighted cover of a magazine was reproduced as a matter of background" would be a fair use), with Ringgold v. Black Entertainment Television, Inc., 126 F.3d 70 (2nd Cir. 1997) (finding no fair use where pictorial work was used for twenty-seven seconds in background of television show).

86. E.g., Monster Commc'ns, Inc. v. Turner Broadcasting Sys., 935 F. Supp. 490 
consideration for those many users who eye global distribution-even a clear Supreme Court interpretation of U.S. law will do little good.

In sum, copyright's doctrinal feedback is most pronounced in big-money industries like film, music, and publishing that combine literal takings with high

costs, deep pockets, and multi-tiered distribution. It takes place regardless of whether copyright owners know about or try to manipulate it, regardless of whether copyright users know and want to do something about it, and regardless of whether the positive law of copyright also expands. This is not to say that doctrinal feedback is not manipulable (it is) or that copyright owners do not manipulate it (they may), or that courts, legislatures, and rent-seeking rightsholders play no purposeful, positivist role in copyright's expansion (they do). But doctrinal feedback is its own animal, an independent contributor to the seemingly ever-expanding reach of the copyright entitlement. It does not depend on developments in legislation or litigation, or on strategic behavior in the marketplace. Rather, it emerges from seemingly innocent structural features of copyright law and from sensible, prudent behavior on the part of everyone involved. Whether we care as a normative matter about this phenomenon is another question, which I will defer until after we examine the role of licensing information in trademark and patent law.

\section{TRADEMARK's FEEDBACK LOOP}

Like copyright law, trademark law has seen a steady expansion over the last few decades, with new subject matters qualifying for its protection, more conduct falling within its entitlements, and additional remedies becoming available to its beneficiaries. Courts and legislatures are responsible for many of these developments ${ }^{87}$ and have received the lion's share of the attention in the scholarship. ${ }^{88}$ Yet trademark's growth is not just the result of formal changes in the positive law. Instead, trademark licensing practices inform trademark law, resulting in an expansive feedback loop rooted in the internal structure of trademark doctrine.

Trademark's doctrinal feedback occurs in three steps. First, courts consider a mark infringed when its unlicensed use is likely to cause confusion among consumers as to whether the mark owner produced, sponsored, or approved of the goods. The definitions of sponsorship and approval, however, are notoriously broad and ambiguous, making liability a significant possibility for

(S.D.N.Y. 1996); Amsinck v. Columbia Pictures Indus., 862 F. Supp. 1044 (S.D.N.Y. 1994). In one case, the defendant vindicated an incidental use almost by accident, having mistakenly thought that the use was licensed. Gordon v. Nextel, 345 F.3d 922, 926 (6th Cir. 2003) (prevailing on de minimis grounds rather than fair use).

87. E.g., Federal Trademark Dilution Act of 1995, Pub. L. No. 104-98, 109 Stat. 985 (1996) (expanding scope of entitlement); Trademark Law Revision Act of 1988, PuB. L. No. 100-667, § 132, 102 Stat. 3935, 3946 (same); W.T. Rogers Co. v. Keene, 778 F.2d 334, 337 (7th Cir. 1985) (recognizing trademark protection for product design).

88. E.g., Robert C. Denicola, Freedom To Copy, 108 YALE L.J. 1661, 1667-68 (1999); Mark A. Lemley, The Modern Lanham Act and the Death of Common Sense, 108 YALE L.J. 1687 (1999); Glynn S. Lunney, Jr., Trademark Monopolies, 48 EMORY L.J. 367 (1999). 
any use of a mark from which consumers might infer acquiescence by the mark owner. In other words, if consumers think that a given use of a mark requires a license from the mark owner, then engaging in that use without a license presents a real risk of liability.

Second, trademark users often seek licenses when none is needed. Sometimes they do so because they are risk averse and do not want to take their chances with trademark's indeterminate doctrines and supracompensatory remedies, much as we have seen in copyright law. Other times they seek licenses not as a mere prophylactic measure, but as part of a mutually beneficial promotional arrangement, like product placement in film and television. In the end, however, the result is the same: licensing markets where none need exist.

Finally, to complete the loop, these licensing markets feed back into the infringement analysis as consumers actively absorb the branding practices they encounter in the marketplace and thus learn over time which trademark uses are licensed. As we will see, a compelling body of empirical studies from the behavioral sciences-never before cited in the trademark literature-suggests that as consumers encounter more and more licensed uses and fewer and fewer unlicensed uses, they will come to view licensing as the norm. And what consumers view as the norm becomes the norm, because consumer perception is trademark law's touchstone.

The end result is that the gray areas of trademark law become less gray-or, more accurately, shift toward uses that had once unquestionably been within the public's prerogative rather than the mark owner's. This feedback effect is less consistent and more attenuated than we saw in copyright, for reasons that will soon become apparent. But it exists nonetheless, and like its copyright counterpart it causes an accretive expansion the reach of trademark entitlements with minimal contributions from courts, legislatures, and rent-seeking rightsholders.

\section{A. Trademark Doctrine}

The prototypical trademark infringement case involves confusion as to the source of the defendant's goods. Suppose an upstart soft drink company uses the "Pepsi" mark on its new cola. By doing so, the upstart passes off its product as that of PepsiCo and confuses loyal Pepsi drinkers into buying its soda, rather than the PepsiCo product they have come to know and love. Trademark law evolved to give mark owners like PepsiCo a way to stop the upstart and thus to prevent harm both to consumers (who are being deceived) and the mark owner (whose sales are being diverted).

Confusion from passing off one producer's product as that of another represents trademark's core concern, but actionable confusion can arise even when consumers clearly understand that the product they are buying did not originate with the mark owner. Modern trademark law forbids not only those uses of a mark that are likely to confuse consumers as to the origin of goods, but also any uses that are likely to cause confusion as to sponsorship or approval of 
the goods. ${ }^{89}$ The case law on sponsorship and approval, however, is so ambiguous as to make it almost impossible to know ex ante whether a given use will be infringing. ${ }^{90}$

The ambiguity begins with imprecise vocabulary. Courts use a variety of synonymous and not-so-synonymous terms to describe the kind of confusion at issue, from the federal Lanham Act's sponsorship and approval terminology, to whether the relationship between the parties is one of endorsement, ${ }^{91}$ affiliation, ${ }^{92}$ association, ${ }^{93}$ connection, ${ }^{94}$ authorization, ${ }^{95}$ permission, ${ }^{96}$ or license, ${ }^{97}$ to whether the use produced confusion "of any kind." 98 Attached to these descriptors comes a host of catch-all modifiers, selected precisely for their imprecision: Was there confusion as to whether the mark owner "otherwise" approved or was "in some other way" connected? ${ }^{99}$ Was there a relationship "of some sort" or a suggestion that the defendant's product emanated "in some way"

89. E.g., 15 U.S.C. $§ 1125$ (a)(1) (prohibiting use of mark that "is likely to cause confusion, or to cause mistake, or to deceive as to the origin, sponsorship, or approval of ... goods, services, or commercial activities").

90. There are other sources of trademark indeterminacy as well, such as the ubiquitous multi-factor test for likelihood of confusion, AMF Inc. v. Sleekcraft Boats, 599 F.2d 341 (9th Cir. 1979), and the uncertain reach of dilution liability, see Lauren P. Smith, Note, Trademarks and the Movies: “An Af- 'Fair Use' To Remember," 48 ClEv. ST. L. ReV. 415 (2000).

91. Pebble Beach Co. v. Tour 18 I Ltd., 155 F.3d 526, 544 (5th Cir. 1998); Boston Athletic Ass'n v. Sullivan, 867 F.2d 22, 28-29 (1st Cir. 1989); Mut. of Omaha Ins. Co. v. Novak, 836 F.2d 397, 398 (8th Cir. 1987); Medic Alert Foundation U.S., Inc. v. Corel Corp., 43 F. Supp. 2d 933, 937 (N.D. Ill. 1999).

92. Pebble Beach, 155 F.3d at 543; Anheuser-Busch, Inc. v. Balducci Publ'ns, 28 F.3d 769, 774 (8th Cir. 1994); Mut. of Omaha, 836 F.2d at 398; Caterpillar Inc. v. Walt Disney Co., 287 F. Supp. 2d 913, 918 (C.D. Ill. 2003); Medic Alert, 43 F. Supp. $2 d$ at 937.

93. Warner Bros., Inc. v. Gay Toys, Inc., 724 F.2d 327, 332 (2d Cir. 1983); Caterpillar, 287 F. Supp. 2d at 918; Schieffelin \& Co. v. Jack Co. of Boca, Inc., 850 F. Supp. 232, 240 (S.D.N.Y. 1994); MGM-Pathe Commc'ns Co. v. Pink Panther Patrol, 774 F. Supp. 869, 873 (S.D.N.Y. 1991); see also Schieffelin \& Co., 850 F. Supp. at 247 ("mental association").

94. Pebble Beach, 155 F.3d at 544; Balducci Publ'ns, 28 F.3d at 774; Boston Athletic, 867 F.2d at 34; Dallas Cowboys Cheerleaders, Inc. v. Pussycat Cinema, Ltd., 604 F.2d 200, 205 (2d Cir. 1979); NFL v. Governor of Del., 435 F. Supp. 1372, 1380 (D. Del. 1977). Courts' use of "affiliation," "association," and "connection" may derive from language in the Lanham Act regarding confusion "as to the affiliation, connection, or association" between the mark user and "another person." 15 U.S.C. $§ 1125(\mathrm{a})(1)(\mathrm{A})$.

95. Processed Plastic Co. v. Warner Communications, Inc., 675 F.2d 852, 854-55 (7th Cir. 1982); Warner Bros., Inc. v. Gay Toys, Inc., 658 F.2d 76, 77 (2d Cir. 1981).

96. Pebble Beach, 155 F.3d at 544; University of Georgia Athletic Ass'n v. Laite, 756 F.2d 1535, 1546 n.28 (11 th Cir. 1985). But see Pebble Beach, 155 F.3d at 544 n.10 (noting that "approval" might have been better term than "permission").

97. Boston Athletic, 867 F.2d at 28-29; Dallas Cowboys, 604 F.2d at 205.

98. Syntex Labs., Inc. v. Norwich Pharmacal Co., 437 F.2d 566, 568 (2d Cir. 1971).

99. Dallas Cowboys, 604 F.2d at 205; see also Boston Athletic, 867 F.2d at 28-29 ("otherwise" endorsed); Mut. of Omaha Ins. Co. v. Novak, 836 F.2d 397, 398 (8th Cir. 1987) ("otherwise" affiliated); Supreme Assembly, Order of Rainbow for Girls v. J.H. Ray Jewelry Co., 676 F.2d 1079 (5th Cir. 1982) (“other" association); Caterpillar Inc. v. Walt Disney Co., 287 F. Supp. 2d 913, 918 (C.D. Ill. 2003) ("otherwise” affiliated); Medic Alert Foundation U.S., Inc. v. Corel Corp., 43 F. Supp. 2d 933, 937 (N.D. Ill. 1999) (“otherwise” affiliated). 
from the mark owner? ${ }^{100}$ Will consumers "in some fashion" associate the plaintiff and defendant? ${ }^{101}$

The choice of terminology does not appear to be result-oriented; courts that favor the defendant use broad language just as readily as courts that favor the plaintiff. ${ }^{102}$ Rather, it seems designed to give courts the flexibility to reach an equitable result despite substantial variation in the fact patterns they encounter. Whether it accomplishes this goal is debatable, much like the question of whether the equitable nature of the fair use doctrine leads to the correct outcome in copyright disputes. As we will see, however, it has the effect of creating substantial gray areas into which the risk-averse trademark user fears to tread.

The ambiguity in terminology leads to further ambiguity regarding the proper focus of the confusion analysis. Under the Lanham Act, the confusion must relate to whether the mark owner sponsored or approved the defendant's product. ${ }^{103}$ But as courts employ a variety of decreasingly analogous synonyms for sponsorship and approval, the focus shifts from whether the plaintiff sponsored or approved of the defendant's product to whether the plaintiff acquiesced in defendant's use of plaintiff's mark. ${ }^{104}$ And some courts seem to

100. Schieffelin \& Co. v. Jack Co. of Boca, Inc., 850 F. Supp. 232, 240, 247 (S.D.N.Y. 1994); see also id. at 247 ("some" mental association); Pebble Beach, 155 F.3d at 544 ("some" connection); Nike, Inc. v. Just Did It Enters., 6 F.3d 1225, 1228 (7th Cir. 1993) ("in some way" related) (quoting James Burrough Ltd. v. Sign of Beefeater, Inc., 540 F.2d 266, 274 (7th Cir. 1976)); Boston Athletic, 867 F.2d at 34 ("some" connection); Caterpillar, 287 F. Supp. 2d at 918 ("somehow" sponsored).

101. MGM-Pathe Commc'ns Co. v. Pink Panther Patrol, 774 F. Supp. 869, 873 (S.D.N.Y. 1991).

102. E.g., compare Just Did It, 6 F.3d at 1228 (reversing judgment for plaintiff regarding confusion as to whether defendant's product was "in some way related to, or connected or affiliated with, or sponsored by" plaintiff) (quoting James Burrough, 540 F.2d at 274), and Supreme Assembly, 676 F.2d at 1082 n.3, 1084 (affirming judgment for defendant regarding confusion as to "connection" and whether defendant's product "was in any way endorsed, sponsored, approved or otherwise associated" with plaintiff), with Anheuser-Busch, Inc. v. Balducci Publ'ns, 28 F.3d 769, 774 (8th Cir. 1994) (reversing judgment for defendant and ordering judgment for plaintiff regarding confusion as to whether defendant's product was "affiliated with, connected with, or sponsored by" plaintiff) (quoting 4 J. THOMAS MCCARTHY, MCCARTHY ON TRADEMARKS AND UNFAIR COMPETITION § 24:03 (3d ed. 1992)), and Schieffelin, 850 F. Supp. at 247 (issuing preliminary injunction based on evidence of confusion as to "association" with and "authorization" by plaintiff and whether defendant's product "emanated in some way" from and evoked "some mental association" with plaintiff).

103. The exact language refers to "confusion ... as to the origin, sponsorship, or approval of his or her goods, services, or commercial activities." 15 U.S.C. $§ 1125(a)(1)$. Note that state statutes may use other, more expansive terms, e.g., GA. CODE ANN. § 10-1-372 (focusing on confusion as to "affiliation, connection, or association with or certification by another"), and that owners of federally registered marks can also proceed under a section of the Lanham Act that contains no limits on the kinds of confusion it deems actionable but that focuses on mark uses directly related to advertising, see 15 U.S.C. $\$ 1114(1)$.

104. E.g., Pebble Beach, 155 F.3d at 544 ("For a party to suggest to the public, through its use of another's mark or a similar mark, that it has received permission to use the mark on its goods or services suggests approval, and even endorsement, of the party's product or service and is a kind of confusion the Lanham Act prohibits."); Dallas Cowboys Cheerleaders, Inc. v. Pussycat Cinema, Ltd., 604 F.2d 200, 205 (2d Cir. 1979) ("The public's belief that the mark's owner sponsored or otherwise approved the use of the trademark satisfies the confusion 
have jettisoned the confusion requirement altogether. ${ }^{105}$

Finally, the indeterminacy culminates in the use of surveys to assess consumer reaction to a disputed use. Courts have come to expect and rely on survey evidence as a matter of course, so much so that their absence is sometimes held against the mark owner. ${ }^{106}$ Yet when it comes to confusion as to sponsorship or approval, surveys rely on the same broad and ambiguous collection of terms that courts use to define the kind of confusion at issue, from whether the defendant's product is "sponsored" or "authorized"107 to whether the mark owner simply "goes along" with the use of the mark. ${ }^{108}$ Perhaps the most popular survey asks the respondent to opine on whether "permission" was required for the challenged use, ${ }^{109}$ which effectively takes consumers' impressions of the relevant licensing culture and converts them into law. Moreover, a mark owner can win its suit by showing a likelihood of confusion among a surprisingly small percentage of the consuming public-as low as ten or fifteen percent. ${ }^{110}$

requirement.").

105. E.g., Boston Athletic Ass'n v. Sullivan, 867 F.2d 22, 33 (1st Cir. 1989) (enjoining sale of t-shirts that suggested link with Boston Marathon without requiring mark owner "to prove that members of the public will actually conclude that defendants' product was officially sponsored by the Marathon's sponsor (whoever that sponsor may be)"); Warner Bros., Inc. v. Gay Toys, Inc., 724 F.2d 327, 33 (2d Cir. 1983) (finding infringement from fact that consumers identified defendant's toy car with car from plaintiff's television show "though there was no showing that consumers believed that the toy cars marketed by [defendant] were sponsored or authorized by [plaintiff]").

106. 5 MCCARTHY, supra note 102, § 32:195.

107. Processed Plastic Co. v. Warner Communications, Inc., 675 F.2d 852, 854-55 (7th Cir. 1982) ("sponsored or authorized"); Schieffelin \& Co. v. Jack Co. of Boca, Inc., 850 F. Supp. 232, 247 (S.D.N.Y. 1994) ("authorization"); NFL Props., Inc. v. Wichita Falls Sportswear, Inc., 532 F. Supp. 651, 661 (W.D. Wash. 1982) ("authorization or sponsorship”); NFL v. Governor of Del., 435 F. Supp. at 1380-81 ("authorization").

108. Mut. of Omaha Ins. Co. v. Novak, 836 F.2d 397, 400-01 (8th Cir. 1987).

109. Permission surveys have been instrumental in dozens of cases, see Jacob Jacoby, Sense and Nonsense in Measuring Sponsorship Confusion 11-14 \& nn.38-39 (N.Y.U. Sch. of Law Law \& Econ. Working Paper No. 29, 2005), available at http://lsr.nellco.org/nyu/lewp/papers/29, but are based on deeply flawed assumptions about the behavior of the actors in the market and grievously oversimplified interpretations of the law. On the factual front, they assume that no business enterprise would seek a license unless the law required it, id. at 8-9, which we will see is demonstrably untrue. On the legal front, they assume that intellectual property law is no different from the law that governs realty and personalty, and that the public thus correctly understands the proper scope of intellectual property rights, $i d$. at 24-26-an argument so facile that it requires no rebuttal. Cf. NFL Props., Inc. v. ProStyle, Inc., 16 F. Supp. 2d 1012, 1018-19 (E.D. Wis. 1998) (ruling permission survey inadmissible because it would "accord trademark protection based upon the public's mistaken notion of the law"); Major League Baseball Props., Inc. v. Sed Non Olet Denarius, Ltd., 817 F. Supp. 1103, 1122-21 (S.D.N.Y. 1993) (finding permission survey questions "leading" and "fatally flawed"), vacated, 859 F. Supp. 80 (S.D.N.Y. 1994).

110. E.g., Mut. of Omaha, 836 F.2d 397 (giving "substantial weight" to survey in which "approximately ten percent of all the persons surveyed thought that [plaintiff] 'goes along' with [defendant's] product"); James Burrough Ltd. v. Sign of Beefeater, Inc., 540 F.2d 266, 278-79 (7th Cir. 1976) (reversing directed verdict when survey showed $15 \%$ of consumers were confused as to plaintiff's sponsorship); Grotrian, Helfferich, Schulz, Th. Steinweg Nachf. v. 
In the end, then, surveys do little more than record consumers' intuitions as to what the law might require. Courts' reliance on such surveys to define the reach of the trademark entitlement thus amounts to a tautological endorsement of whatever consumers believe the law is, or should be, regardless of whether their beliefs make any sense from a policy standpoint. Instead of telling the public what the law has to say about the legality of unlicensed trademark uses, courts instead ask the public.

Thus we see that trademark doctrine opens itself up to the same circularity that we saw in copyright law. The reach of the entitlement depends on consumer perception. If that perception is formed at least in part by exposure to licensing practices, then the law conflates premise and conclusion and invites doctrinal feedback. ${ }^{111}$ To close this loop and show that it expands the entitlement, however, we need two more ingredients: licensing markets where none is needed, and a means of feeding that licensing information back into consumer perception. I will consider each in turn.

\section{B. Licensing Motivations}

We have just seen that the boundaries of trademark rights, like their copyright counterparts, are indeterminate. And like copyright law, trademark law not only provides supracompensatory monetary remedies ${ }^{112}$ but also strongly presumes that prevailing rightsholders deserve injunctions, both preliminary and permanent. ${ }^{113}$ It should therefore come as no surprise when trademark users who could mount a decent defense against an infringement claim nevertheless choose to seek a license. This is particularly true for moneyed, risk-averse actors like movie and television producers; from their perspective, or that of their E\&O insurer, it makes no difference whether the court order that brings the project to a screeching halt originates in trademark law or copyright law. Filmmakers accordingly approach trademark licensing as conservatively as they approach copyright licensing, ${ }^{114}$ with "license, don't litigate" drilled into their heads starting in film school. ${ }^{115}$

Yet risk aversion and the fear of being sued provide only part of the

Steinway and Sons, 365 F. Supp. 707, 716 (S.D.N.Y. 1973) (finding "strong evidence" of likelihood of confusion where $7.7 \%$ of those surveyed "preceived [sic] a business connection" between the parties and " $8.5 \%$ confused the names").

111. See 4 MCCARTHY, supra note 102, § 24:9; Denicola, supra note 88, at 1667-68; Stacey L. Dogan \& Mark A. Lemley, The Merchandising Right: Fragile Theory or Fait Accompli?, 54 EMORY L.J. 461, 485-86 (2005); Lemley, supra note 88, at 1708; Lunney, supra note 88, at 39697.

112. E.g., 15 U.S.C. §§ 1114(1)(a), 1117.

113. E.g., Int'1 Kennel Club of Chicago, Inc. v. Mighty Star, Inc., 846 F.2d 1079, 1084 (7th Cir. 1988) ("At the preliminary injunction stage, ... a [trademark] plaintiff need only demonstrate that he or she has a 'better than negligible' chance of succeeding on the merits to justify injunctive relief.”); NFL Props., Inc. v. Wichita Falls Sportswear, Inc., 532 F. Supp. 651, 664 (W.D. Wash. 1982) (ordering permanent injunction in merchandising dispute as "the standard remedy in unfair competition cases").

114. HEINS \& BECKLES, supra note 24, at 20-21.

115. Id. at 18 . 
explanation for the existence of unneeded trademark licenses. Mutually advantageous business opportunities also create licensing markets. Merchandising provides a good example. Consider Triangle Publications, Inc. $v$. Rohrlich, ${ }^{116}$ one of the first cases to recognize the viability of a claim of sponsorship confusion. Triangle Publications published Seventeen, the wellknown magazine for teenage girls. Rohrlich sold girdles under the trademark "Miss Seventeen." "117 Triangle sued Rohrlich for trademark infringement. Although Triangle was in the business of selling magazines, not clothing, the Second Circuit placed great weight on the district court's finding that the "Seventeen" mark

had played an important part in the merchandising of teen-age apparel in various ways, such as by conferences with manufacturers, editorial fashion comments, sales to manufacturers and merchandisers of reprints, countercards and blow ups of its comments and of advertising, monthly bulletins advising merchandisers how to tie in with forthcoming issues of the magazine, and by aiding merchandisers in arranging window displays and departmental displays. ${ }^{118}$

The court accordingly concluded that "the public was likely to attribute the use of 'Seventeen' in connection with sales of teen-age merchandise to the plaintiff as a source of sponsorship" and affirmed a judgment against Rohrlich. ${ }^{119} \mathrm{We}$ can infer that the merchandising relationships that were so important to the case's outcome came about not because the various manufacturers and merchandisers engaged in merely prophylactic licensing, but because they genuinely wanted to strike a symbiotic promotional deal with a popular periodical. ${ }^{120}$

Similar promotional arrangements occur in the entertainment industry, where producers strike "product placement" deals with mark owners-not because they necessarily have to, as a legal matter, but because the deals represent money-making opportunities. If our Cleveland documentarian is worried about whether the appearance of the "Newsweek" mark in her film will lead to sponsorship or approval liability, she can call Newsweek Inc. and offer to pay a fee for a trademark license. But why not instead ask the mark owner to pay her a fee? Manufacturers are increasingly arranging (and paying) for the conspicuous use of their products or appearance of their logos in popular media. A seven-second close up of Sunlight brand detergent on the sitcom Everybody

116. 167 F.2d 969 (2d Cir. 1948).

117. Id. at 970 .

118. Id. at 971 .

119. Id. The holding technically rested on a finding of unfair competition; the court declined to reach the trademark issue. Id. at 971.

120. A similar phenomenon may cause a feedback-fueled expansion of rights of privacy and publicity at the expense of the public domain: authors and filmmakers who recount factual events may strike a deal with those whom they depict, not because they fear litigation, but because "the persons involved may have information that would otherwise be hard to find out and can serve a promotional role ." DONALDSON, supra note 23, at 48 (noting that insurers may now insist on such clearances). 
Loves Raymond cost over $\$ 20,000 .{ }^{121}$ On Friends, a lengthy product placement for Snuggle fabric softener cost ten times that much-but for that price one of the characters actually handled the package. ${ }^{122}$ In the late $1990 \mathrm{~s}$, product placement routinely generated an estimated fifteen percent of Hollywood's feature film revenue, and more recent studies suggest the figure has risen to twenty-five percent. ${ }^{123}$ For one recent James Bond film, MGM enlisted over twenty marketing partners for a total of at least \$100 million, \$35 million of which came from Ford Motor Company alone. ${ }^{124}$

In short, risk aversion and promotional opportunities combine to create markets for trademark licenses where none is needed. As we will soon see, these two different motivations for licensing have different implications for how strong trademark's feedback effect will be.

\section{Persuasion Knowledge}

We now have two of the three pieces of trademark's feedback puzzle: an ambiguous infringement doctrine that depends on consumer perception, and unneeded licensing markets. Now we must connect the dots: the licensing markets must cause consumer perception to change, so that perception feeds back into doctrine.

This final step is the least intuitive, because trademark law tends to view consumer perception as static and consumers as gullible dupes, helpless to deal with even marginally confusing marketing practices. For example, an unlicensed mark user can easily lose an infringement suit even when ninety percent or more of the public is not confused by the use. ${ }^{125}$ And the case law often views consumers as incapable of learning from past encounters with trademarks. One line of cases holds that an Internet search engine cannot show Toyota advertising when its users search for "Honda," under the rationale that consumers will blithely assume that advertisements accompanying search results will relate only to the brand for which the search was conducted. ${ }^{126}$ These holdings ignore the obvious: those who operate under that assumption will quickly (and relatively costlessly) be disabused of it the first time they click on such an ad and see only Toyota products, and will presumably adjust their expectations thereafter so as not to be confused again. ${ }^{127}$

121. Louis Chunovic, Trying To Price Placement, Advertising Age, Dec. 2, 2002, at 4. 122. Id.

123. Kim Bartel Sheehan \& Aibing Guo, "Leaving on a (Branded) Jet Place": An Exploration of Audience Attitudes Towards Product Assimilation in Television Content, J. CURRENT IsS. \& RES. IN ADVERTISING, Spring 2005, at 79, 80.

124. Jane Weaver, A License to Shill, MSNBC News (June 16, 2003), http://msnbc.msn.com/id/3073513.

125. See sources cited supra note 110.

126. E.g., Playboy Enters., Inc. v. Netscape Communications Corp., 354 F.3d 1020 (9th Cir. 2004); Edina Realty, Inc. v. TheMLSonline.com, No. Civ. 04-4371JRTFLN, 2006 WL 737064 (D. Minn. Mar 20, 2006).

127. See Stacey L. Dogan \& Mark A. Lemley, Trademarks and Consumer Search Costs on the Internet, 41 Hous. L. REV. 777, 823 (2004). 
A compelling body of empirical studies from the behavioral sciences-never before cited in the intellectual property scholarship-teaches us that such adjustments of consumer expectation are common. Consumers routinely develop an awareness of the promotional nature of the marketing efforts that bombard them and an ability to appreciate and manage their own reactions thereto. ${ }^{128}$ This ability on the part of consumers, called "persuasion knowledge," should come as no surprise. The average consumer encounters some three thousand brand names a day. ${ }^{129}$ That's three thousand opportunities for the consumer to learn about trademark practices.

When it comes to learning about sponsorship or approval, for example, consumers cannot help but notice the proliferation of cross-promotional arrangements in the mass media, where obviously unconnected enterprises constantly associate with one another in a clearly "official" capacity. The Eddie Bauer logo adorns the side of a Ford SUV. Xerox sponsors the Olympic Games. A single television commercial advertises both the NBA playoffs and the latest Hollywood blockbuster, incorporating and interspersing footage from both. When consumers experience these promotional efforts, they draw certain conclusions about the interaction of mark owners and the law that governs sponsorship, and stand ready to apply that new persuasion knowledge to the next marketing tool they encounter. Changes in licensing practices can therefore effect changes in consumer perception. Any given analysis of how consumers perceive a trademark use-for example, a consumer survey, or a court ruling that relies on such a survey-represents a mere snapshot of a moving target, whose perception may be quite different after new licensing practices work their magic. ${ }^{130}$

The strength of trademark's feedback effect accordingly depends on how easy it is for consumers to acquire persuasion knowledge about trademark practice. When consumers readily understand that a given use is licensed, the entitlement will more easily and organically expand to include that sort of use. When such an understanding is harder to come by, accretive expansion is slower, or altogether absent. A review of trademark's doctrinal feedback in the film and television industry and the merchandising industry will demonstrate this point.

128. For the foundational research, see Marian Friestad \& Peter Wright, The Persuasion Knowledge Model: How People Cope with Persuasion Attempts, 21 J. CONSUMER Res. 1 (1994).

129. Michelle R. Nelson \& Laurie Ellis McLeod, Adolescent Brand Consciousness and Product Placements: Awareness Liking and Perceived Effects on Self and Others, 29 INT'L J. CONSUMER STUD. 515, 516 (2005).

130. "All people are 'moving targets' whose knowledge about persuasion keeps changing," making it risky to "rely[] on subjects who are uniformly at any particular stage of persuasion knowledge development." Friestad \& Wright, supra note 128, at 23. 


\section{Film and Television}

Suppose Aidan Auteur makes a film in which the hero chugs a can of Red Bull energy drink. Would a consumer be confused as to whether the maker of Red Bull sponsored the film? Maybe not. We might even say probably not. ${ }^{131}$ But as we have seen, the law is sufficiently ambiguous and Aidan sufficiently risk averse that he may decide not to take any chances with his investment. He will either forgo the use of the brand-name product or get a license from the mark owner. As it happens, each of these options affects the persuasion knowledge consumers will acquire about trademark practices in the film industry. If he simply substitutes a glass of water or some fictional brand for the Red Bull, viewers might never notice and would thus acquire little persuasion knowledge about the trademark considerations that guided his decision. Likewise, if he secures a license to use the brand, but its use remains incidental and inconspicuous, then consumers will again draw few conclusions from its appearance. These options therefore suggest a weak feedback effect-although even in these two cases some persuasion knowledge results: if other filmmakers follow suit, recognizable brands will only rarely be prominently featured in movies and will consequently be more noticeable to the public when they do.

Aidan's remaining two options affect consumer perception more directly and thus produce stronger feedback. First, suppose he uses digital pixels to blur the image of the can so that the Red Bull brand is not recognizable (an increasingly common and accessible practice, particularly in "reality" television and documentaries). ${ }^{132}$ Such pixelation sends a strong signal to viewers that

131. On this precise point, the case law favors unlicensed use. In 2003, the owner of the well-known "Caterpillar" mark for earth-moving equipment lost a motion for a temporary restraining order against Disney's release of George of the Jungle 2, in which Caterpillar bulldozers were shown poised to wreak environmental havoc on George's beloved Ape Mountain. Caterpillar Inc. v. Walt Disney Co., 287 F. Supp. 2d 913, 916-18 (C.D. Ill. 2003). Although the court that Caterpillar had a "slightly more than negligible likelihood of success" on its confusion claim, $i d$. at 920, that was not enough to outweigh the harm to Disney that would result from issuance of the order, $i d$. at 923 . That said, the court indicated that its holding might change as licensing practices change: "Part of what drives the Court's discomfort with Caterpillar's position is the fact that the [unlicensed] appearance of products bearing well known trademarks in cinema and television is a common phenomenon." Id. at 919. And there is sufficient contrary precedent to render the issue ambiguous: one of the best-known and most expansive sponsorship cases held that trademark law forbade the unlicensed use of an NFL cheerleading uniform in the pornographic film Debbie Does Dallas, although that ruling also focused on the use of the uniform in the film's promotion. Dallas Cowboys Cheerleaders, Inc. v. Pussycat Cinema, Ltd., 604 F.2d 200, 203 (2d Cir. 1979) (affirming preliminary injunction). Experienced trademark counsel will also notice that Caterpillar failed to conduct the allimportant consumer survey-a mistake not likely to be repeated in the latest challenge to an unlicensed use of a mark in a Disney films, this one from the Hell's Angels. Hells Angels Sue Disney on Planned Movie, N.Y. TIMES, Mar. 11, 2006, at C4. Indeed, the fact that Caterpillar even bothered to bring suit may be more significant than the fact that it lost.

132. HEINS \& BECKLES, supra note 24, at 21 (quoting filmmaker for proposition that "[y]ou see everything being blurred now, because for the first time, we're able to do that technically without it being a big deal"'). Reality television has also proved to be a favorite locus for Aidan's other option, product placement. Amanda Bronstad, Paying for a Place, NAT'L L.J., May 1, 
trademarks have some special legal status-i.e., that filmmakers are not free to use them as they please-because viewers cannot help but notice that a brand has been blurred. ${ }^{133}$

Second, suppose he secures a license as part of a product placement deal with the owner of the Red Bull mark. Such product placement may have once been a clandestine form of marketing whose effectiveness depended on its ability to promote a product to consumers when their usual skeptical defenses against advertising were down. ${ }^{134}$ But persuasion knowledge studies in the last fifteen years repeatedly show that consumers have become more sophisticated in interpreting product placement; they have grown aware of the practice and are adjusting their attitudes as "active interpreters, not passive receptors of encountered brands." "135 Hollywood has adapted as well, making crosspromotion something it trumpets rather than hides. ${ }^{136}$ Hit films like The Truman Show and Wayne's World even satirize the (formerly) manipulative nature of product placement with jokes that assume audience familiarity with the practice. ${ }^{137}$ In short, today's audiences have learned to view branded products in movies and television programs as more than mere incidental props, and are more likely to assume that prominently featured brands are licensed by the mark owner.

Thus doctrinal feedback is born. Risk aversion and product placement lead to more licensing and less depiction of unlicensed brands. Viewers pick up on at least some of these practices, such as increasingly obvious placements and eye-catching pixelated images. Over time, then, consumers come to see

2006, at 1,18 .

133. Cf. Shelley E. Taylor \& Susan T. Fiske, Point of View and Perceptions of Causality, 32 J. PeRsonAlity \& SOC. Psychol. 439, 445 (1975) (explaining strong tendency to draw causal inferences from information to which one's attention is drawn).

134. Friestad \& Wright, supra note 128, at 14; Nelson \& McLeod, supra note 129, at 516.

135. Denise E. DeLorme \& Leonard N. Reid, Moviegoers' Experiences and Interpretations of Brands in Films Revisited, J. Advertising, Summer 1999, at 71, 85; see also id. at 78 (observing that moviegoers in study "were aware of the persuasive intent of brand props"), 85 ("Our results convincingly demonstrate that moviegoers are more sophisticated in their understanding of the practice of brand placement than critics would have public policy officials believe."); Israel D. Nebenzahl \& Eugene Secunda, Consumers' Attitudes Toward Product Placement in Movies, 21 INT'L J. ADVERTISING 1, 5-6 (1993) (reporting that college students are neutral on whether product placement is unethical and that only $6.7 \%$ view it as misleading); Sheehan \& Guo, supra note 123, at 83 (noting that "audiences grow more aware of product placement given its explicit presence in the content, and may develop attitudes toward the practice"); Michelle Nelson \& Mark Rademacher, How Media Create Persuasion Knowledge: An Analysis of Product Placement Coverage in Trade and Newspaper Print Media 16 (Feb. 15, 2006) (unpublished manuscript, on file with author) (noting that media coverage twenty years ago was likely to focus on the "newness" of product placement whereas more recent coverage assumes that readers "are familiar with the practice"); $c f$. Paul Siegel, Product Placement and the Law, in Handbook of Product Placement in the Mass Media 89, 97 (Mary-Lou Galician ed., 2004) (noting that product placements ma have been clandestine fifteen years ago "[b]ut nowadays, audiences are keenly aware of their existence").

136. Debra Goldman, Wheels of Fortune, ADwEEK, Apr. 14, 1997, at 62; Sheehan \& Guo at 80.

137. Siegel, supra note 135 , at 97. 
licensing as the norm: if a brand appears in a film, its owner must have consented. Indeed, some forty-three percent of consumers already regard the appearance of a branded product in a television program as an attempt to influence the product's purchase. ${ }^{138}$ Those giving advice to the major players in film and television recognize that this persuasion knowledge implies broader trademark rights and act accordingly. For example, MTV long-form programming policy requires pixelation of any prominently featured brand that is not part of a product placement deal, so that viewers will not mistakenly think that it is-a policy that the network's intellectual property counsel admits is "based largely on a business decision to avoid a risk of claim/litigation and not a concrete belief that it's illegal." "139 Such conservative licensing practices, prudent as they may be, push trademark's entitlement even further into previously unregulated territory.

\section{Merchandising}

The considerable growth of trademark's reach in the merchandising industry over the last thirty years provides another opportunity to study the role of persuasion knowledge in doctrinal feedback. Licensing trademarks for use on clothing, keychains, coffee cups, and other assorted merchandise is a multibillion-dollar business. Yet a mark owner's right to demand payment for use of its mark on such goods is of recent vintage and arises from a series of ambiguous rulings. 140

The earliest of those rulings looked to licensing evidence in deciding whether the mark owner controlled the merchandising market. For example, the first litigation victories for sports merchandising came about because the NFL and NHL had each given one manufacturer an exclusive license to make embroidered team logos. When unlicensed companies began to sell the same product, the leagues sued. ${ }^{141}$ In each case, the court attached considerable significance to the fact that the leagues had already created and exploited a market for exclusive licenses, such that consumers would be confused by unlicensed uses ${ }^{142}$-an implicit recognition that consumers had internalized the licensing practices in that industry. Thus those markets that prominently featured "official" merchandise and that did not have a tradition of unlicensed competition were fertile ground for claims that all goods bearing a trademark had to be licensed. ${ }^{143}$

138. Dawn Anfuso, Survey Says: TV Ads Not Dead, IMEdia ConNECTION, Aug. 22, 2005, at http://www.imediaconnection.com/news/6577.asp (last viewed Feb. 13, 2006).

139. E-mail from Vate Powell, Vice President and Senior Counsel for Intellectual Property and Litigation, MTV Networks, to James Gibson, Director of Intellectual Property Institute and Assistant Professor of Law, University of Richmond School of Law (June 26-27, 2006) (on file with author). Powell also believes that this is "an industry practice and not just ours." Id.

140. See generally Dogan \& Lemley, supra note 111.

141. Boston Prof'1 Hockey Ass'n v. Dallas Cap \& Emblem Mfg., Inc., 510 F.2d 1004 (5th

Cir. 1975); NFL Props., Inc. v. Consumer Enters., Inc., 327 N.E.2d 242 (Ill. App. 1975).

142. Boston Prof'l Hockey, 510 F.2d at 1011; Consumer Enters., 327 N.E.2d at 246.

143. As one court reluctantly concluded, "Apparently, in this day and age when professional 
The earliest cases to reject a merchandising claim applied the same principle (or, more precisely, its inverse). Here, the mark owners' failure to show that the market for college paraphernalia and fraternal merchandise was exclusive to their licensees doomed their claims. The absence of such a market meant that consumers were accustomed to encountering unlicensed merchandise and thus would not mistakenly infer any relationship between the merchandise manufacturer and the mark owner simply by virtue of the mark's appearance on a product. $^{144}$ Again, the importance of persuasion knowledge was clear: consumers had learned from the lack of exclusive licensing in those industries and formed their expectations accordingly.

Despite their restrictive holdings, however, the courts that rejected early merchandising claims created the potential for a feedback-fueled expansion of the trademark entitlement. They used broad and vague definitions of actionable confusion, thereby creating uncertainty as to how far outside their facts the holding applied. ${ }^{145}$ And their narrow rulings often based the rejection of broad merchandising rights on the absence of any formal testing of consumer reaction to the disputed use, which invited the use of that insidious and circular instrument of trademark expansion, the consumer survey. ${ }^{146}$ Within these decisions therefore lurked the danger that the trademark entitlement would move further into the merchandising realm, beyond where the case law indicated-even without any more court rulings or other positivist developments. Exclusive licensing might initially be uncommon in a given market, but over time that could easily change, and consumer perception would change with it. The shift might begin with symbiotic licensing, as when a merchandiser sees value in becoming an "official" licensee. Other merchandisers might then license prophylactically, having recognized the ambiguity of the legal standards

sports teams franchise pennants, teeshirts, helmets, drinking glasses and a wide range of other products, a substantial number of people believe, if not told otherwise, that one cannot conduct [a state lottery based on NFL games] without NFL approval." NFL v. Governor of Del., 435 F. Supp. 1372, 1381 (D. Del. 1977); see also NFL Props., Inc. v. Wichita Falls Sportswear, Inc., 532 F. Supp. 651 (W.D. Wash. 1982) (enjoining unlicensed NFL jerseys); Dallas Cowboys Cheerleaders, Inc. v. Pussycat Cinema, Ltd., 604 F.2d 200 (2d Cir. 1979) (affirming preliminary injunction against use of Dallas Cowboys cheerleaders uniform in adult film); $c f$. Boston Athletic Ass'n v. Sullivan, 867 F.2d 22 (1st Cir. 1989) (ordering summary judgment against maker of tshirts that suggested connection with Boston Marathon).

144. Supreme Assembly, Order of Rainbow for Girls v. J. H. Ray Jewelry Co., 676 F.2d 1079, 1083 (5th Cir. 1982) (fraternal merchandise); Int'l Order of Job's Daughters v. Lindeburg and Co., 633 F.2d 912, 920 (9th Cir. 1980) (same); Board of Governors of the University of North Carolina v. Helpingstine, 714 F. Supp. 167 (M.D.N.C. 1989) (college merchandise); University of Pittsburgh v. Champion Products, Inc., 566 F. Supp. 711, 716 (W.D. Pa. 1983) (same). But see University of Georgia Athletic Ass'n v. Laite, 756 F.2d 1535 (11th Cir. 1985) (finding infringement from use of university mascot on beer).

145. E.g., Supreme Assembly, 676 F.2d at 1082-83 \& n.3 (speaking of confusion as to source, endorsement, sponsorship, connection, approval, or "other association"); University of Pittsburgh, 566 F. Supp. at 713 (looking for confusion as to "origin, sponsorship, endorsement, or any other nature").

146. E.g., Helpingstine, 714 F. Supp. at 173 (M.D.N.C. 1989) (suggesting that survey like that in Wichita Falls would have helped mark owner's case); University of Pittsburgh, 566 F. Supp. at 720 (same). 
and the risk of an adverse judgment (a risk that would only increase as more symbiotic licensing occurred). Eventually, as consumers encountered more "official" licensed merchandise and less unlicensed merchandise, they would increasingly come to believe that the law required a license for the use of a mark on a given good. This new persuasion knowledge would then work its way back into trademark practice through the law's use of consumer perception to define the entitlement's reach.

Thus a feedback effect that got its start through purely voluntary, mutually beneficial licensing agreements would pick up speed and extend the reach of the entitlement into the sphere of those who would prefer to compete with, not contract with, the mark owner. We saw this feedback effect in the Triangle Publications decision discussed above, in which the unlicensed defendant found himself stymied by licensing practices that others had eagerly created as part of merchandising deals with Seventeen magazine. ${ }^{147}$ We have also seen that feedback was responsible for the first incursions of exclusive rights into the realm of professional sports merchandise; the NFL's and NHL's success in persuading some merchandisers to seek licenses is what ensured their victories in subsequent litigation against others.

In Triangle Publications and the professional sports cases, we can point to feedback as the culprit with some certainty because courts explicitly cited these licensing markets in crafting their expansive rulings. The more difficult question is whether we can detect doctrinal feedback that never circles back around into the positive law. The development of a vibrant merchandising industry suggests that the answer is yes. Few merchandising cases have been decided since the initial wave discussed above. One statutory change has occurred at the federal level ("sponsorship" and "approval" were added to section 43(a) of the Lanham Act about a dozen years after the first merchandising rulings ${ }^{148}$, yet this amendment simply codified established case law and thus made little difference to positive law as a whole. ${ }^{149}$ Yet despite this relative stasis in the positive law, colleges-whose attempts to establish merchandising exclusivity in court were largely rejected-now oversee a billiondollar licensing market. ${ }^{150}$ Indeed, merchandising exclusivity is so widely accepted today that police routinely raid unlicensed merchandisers and "trademark owners, retail businesses, and even government officials simply assume the existence of such a right." ${ }^{\prime 151}$ Scholars have been at a loss to explain these developments. ${ }^{152}$ If the law has not changed, what has? The answer, I

147. See supra notes $116-120$ and accompanying text.

148. Trademark Law Revision Act of 1988, PuB. L. No. 100-667, § 132, 102 Stat. 3935, 3946 (amending 15 U.S.C. § 43(a)).

149. Lunney, supra note 88 , at $474 \&$ n. 353 .

150. 1 Gregory J. Battersby \& Charles W. Grimes, The LaW of Merchandise and CHARACTER LICENSING $§ 2: 16$ (2005).

151. Dogan \& Lemley, supra note 111, at 478.

152. E.g., id. ("The fact that courts are at best evenly split as to whether a merchandising right even exists-and even more dubious of its existence in the absence of consumer confusion-makes it all the more surprising that trademark owners, retail businesses, and even government officials simply assume the existence of such a right.") (footnote omitted). 
submit, is that symbiotic licensing and prophylactic licensing both naturally develop in merchandising markets-the former driven by promotional opportunities and the latter by risk aversion and the indeterminacy of infringement's reach. Consumer persuasion knowledge develops apace, and as consumers develop expectations more favorable to expansive merchandising rights, mark users have even more reason to seek licenses, which in turn fuels more expansion, and so on.

\section{Limitations on Trademark's Feedback}

Although I hope to have convinced readers by now that doctrinal feedback plays a significant and unappreciated part in the expansion of trademark entitlements, the phenomenon comes with some caveats. In this final trademark section, I discuss these caveats and explain why they will not ultimately curtail trademark's accretive growth.

I begin with the limitations of the persuasion knowledge model. Recall that trademark doctrine, unlike copyright doctrine, does not refer directly to licensing markets; rather, licensing informs doctrine only through the admittedly hazy filter of consumer perception. The persuasion knowledge model explains how consumers come to understand and internalize the licensing practices they encounter. It therefore constitutes a vital part of the feedback loop.

As we have seen, however, certain licensing practices are easier for the consumer to observe and absorb than others, and it is hard to predict with any consistency when and how consumers will become aware of licenses in the first place, let alone whether that awareness will translate into expansive impressions of trademark's reach. For example, consumers who encounter a Lakers sweatshirt with a prominent "Official NBA Product" label might not notice the label at all and thus gain no persuasion knowledge from it. Of those who do notice, some might infer from the label that a license is necessary to produce branded merchandise-an inference that could fuel accretive expansion. On the other hand, other consumers might infer that the label means that the market includes unofficial gear too-otherwise, why would the distinction be made? That inference would militate against accretive expansion. Likewise, a riskaverse filmmaker may choose to pixelate an unlicensed mark or reach a product placement deal to feature it prominently; either use conspicuously implies licensing rules that consumers could easily internalize. But if the filmmaker instead relegates the mark to the background or forgoes its use entirely, consumers are not likely to gain much persuasion knowledge. We should therefore expect accretive expansion of trademark entitlements to be more halting and sporadic than its copyright counterpart.

Another problem with using the persuasion knowledge model to connect licensing practices to consumer perception is that consumers acquire persuasion knowledge from sources other than the licensing they encounter. In one 1983 poll, $91.2 \%$ of respondents agreed that " $[\mathrm{n}]$ o product can bear the name of an entertainer, cartoon character, or some other famous person unless permission is 
given for its use by the owner of the name or character" $" 153$ - an impression that is hard to explain based purely on the licensing practices of the time. Likewise, consumers learn about product placement from repeated exposure to it, but they also learn from media coverage of the practice, which has increased over the last twenty years. ${ }^{154}$ These extrinsic sources of persuasion knowledge will make little difference if they simply reinforce the impressions that consumers get from licensing practices. But if they overstate the prevalence of licensing, they may increase the feedback effect-causing a growth in the entitlement that is neither internal to trademark doctrine nor predictive of future expansion. If they understate it, they may slow feedback down, or even cause accretive contraction of entitlements.

Another potential wrench in feedback's gears is the fact that trademark licensing is only partly responsive to trademark doctrine. Product placement deals and the symbiotic licensing we saw in merchandising cases arise not because of worries about trademark liability, but because both parties see value in cross-promotion. There is accordingly no guarantee that such licensing will arise in any given market-and without licensing, there is no feedback. Even prophylactic licensing, which is rooted in fear of liability, may not be as strong in trademark as in copyright. Someone selling knock-off Lakers jerseys has lower costs than the filmmaker who wants to excerpt four lines from a Springsteen song, and in any event is more likely to be a somewhat shady character with a high internal discount rate. ${ }^{155} \mathrm{He}$ or she will therefore be more willing to roll the dice and risk litigation.

This does not mean that trademark experiences no doctrinal feedback-trademark users like our filmmaker will be risk averse, and even a risk-neutral actor may choose to seek a license in the face of considerable legal ambiguities-but its effect may be less widespread and more attenuated in industries that lack strong risk aversion. We can expect feedback in such industries to be particularly dependent on developments in the positive law, because the absence of risk aversion means that a licensing culture is unlikely to spontaneously arise without an apposite and expansive court ruling or statute. Such dependence would not curtail the feedback effect, but it would make it less insidious and more like the positivist entitlement expansions on which the scholarship usually focuses. ${ }^{156}$

153. Stephen H. Harrison, The Merchandising Reporter's First Consumers Survey on Licensing, MERCHANDISING REP., Aug. 1983, at 22, 23-25. The survey results demonstrate the potential for a feedback-fueled expansion of trademark's cousin, the right of publicity.

154. Nelson \& Rademacher, supra note 135.

155. See James Cyphers, Companies Join Police in Pursuing T-Shirt Bootleggers, WALL ST. J., Sept. 4, 1991, at B2 ("The T-shirts are cheap to make, the stolen trademarks are free and the risk of getting caught is still low.").

156. See, e.g., Lemley, supra note 88, at 1697-1705 (discussing the role of positive law in trademark's "doctrinal creep"). The positive law might also be an additional source of persuasion knowledge, but the average consumer is undoubtedly more likely to feel the effects of court decisions and new legislation through exposure to updated licensing practices than through hearing about them directly. But see Denicola, supra note 88, at 1667-68 (arguing that trademark's "self-actuated expansion" results from "trademark owners who win enough 
Finally, even if trademark law contains the seeds of its own expansion, the skeptic might argue that another extrinsic influence, the First Amendment, will prevent courts from extending the reach of the entitlement, particularly when it affects the expressive decisions of filmmakers and other artists. This is possible, but far from certain. Although trademark law is essentially the regulation of expression, it has traditionally withstood constitutional scrutiny because its regulations apply only when consumers are deceived, and the First Amendment permits regulation of deceitful speech (e.g., perjury and fraud). ${ }^{157}$ The Second Circuit, for example, gave constitutional concerns short shrift when it affirmed an order-a prior restraint-barring release of the defendant's film: "The propriety of a preliminary injunction where [protection of trademark's property right] is sought is so clear that courts have often issued an injunction without even mentioning the first amendment." ${ }^{158}$ Given this precedent, the malleable definition of actionable confusion, and the low evidentiary threshold for survey proof, the First Amendment is not a reliable obstacle to the accretive expansion of trademark rights in film and television content. ${ }^{159}$

If the First Amendment does not halt the intrusion of trademark into popular culture, that intrusion has the potential to fuel feedback in other settings as well. Film and television represent the public's primary interaction with trademarks outside their traditional role as mere indicators of origin. The persuasion knowledge consumers acquire from mass media and its risk-averse, promotionminded actors will therefore disproportionately inform their perception of trademark rights in broader contexts. Already sixty-five percent of magazine readers think that editorial mentions of a brand are the result of a deal between the mark owner and the magazine. ${ }^{160}$ And product placement is creeping into videogames, ${ }^{161}$ rap music, ${ }^{162}$ and even novels. ${ }^{163}$ The practice has even sparked a guerilla movement of sorts that encourages the negative depiction of brands as

high-profile cases or brag loudly enough about licensing revenues from ornamental use").

157. See Robert C. Denicola, Trademarks as Speech: Constitutional Implications of the Emerging Rationales for the Protection of Trade Symbols, 1982 WIS. L. REV. 158, 160-64.

158. Dallas Cowboys Cheerleaders, Inc. v. Pussycat Cinema, Ltd., 604 F.2d 200, 206 (2d Cir. 1979).

159. Contrast this with dilution theory, which is often cited as trademark's greatest threat to free expression and autonomy. E.g., Denicola, supra note 157, at 195-206 (focusing on dilution by tarnishment); see also Smith, supra note 90 (arguing that dilution law already gives trademark owners too much control over use of branded products in film). Trademark dilution, however, does not require proof of consumer confusion and thus is more vulnerable to First Amendment attack. The accretive, confusion-based expansion I describe may therefore be more threatening to expressive freedom than the positive law of dilution.

160. The Week, Advertising Age, Oct. 17, 2005, at 20 (Sheila Dougherty ed.).

161. Mike Musgrove, Advertisers Are Getting Into the Game, WASH. Post., Mar. 2, 2006, at D1.

162. Krissah Williams, In Hip-Hop, Making Name-Dropping Pay, Wash. Post., Aug. 29, 2005, at D1; Hank Kim, Def Jam, H-P Explore Branded Music Alliance, Advertising Age, Sept. 9, 2002, at 4 .

163. Steven L. Snyder, Note, Movies and Product Placement: Is Hollywood Turning Films into Commercial Speech, 1992 U. ILL. L. REV. 301, 308 (discussing the pre-arranged appearance of a Maserati in the novel Power City). 
a way of resisting the reach of intellectual property rights. ${ }^{164}$

In short, despite the preceding caveats, mark owners' control over use of marks in popular culture and elsewhere is likely to grow. We begin with virgin territory, in which those who choose to enter into symbiotic promotional deals with mark owners coexist peacefully with those who opted instead for unlicensed uses. But as licensing deals and pixelated brands become more pervasive and more apparent to consumers, what was once a voluntary relationship between mark owner and user begins to shift. Consumers draw more inferences from the appearance of brands, and their inferences then feed back into the legal calculus in which practitioners engage when deciding whether to license. In the end, mark users will have to pay fees to mark owners without getting anything out of it but the "right" to use the branded good-a "right" for which a license was never needed before.

\section{PATENT’s SHORT CIRCUIT}

Like copyright and trademark, patent is home to legal ambiguities, risk aversion, costly litigation, severe penalties, and a doctrine that looks to the existence vel non of licensing markets in defining entitlements. Yet because of the manner in which these factors interact, and because of courts' sensitivity to their interaction, they do not produce systemic accretion of rights-despite the fact that unnecessary licensing does take place. I will therefore spend only a short time examining doctrinal feedback in patent law, lingering just long enough to learn how licensing information can contribute to intellectual property doctrine without causing an accretive expansion of rights.

The ambiguities that lead to unnecessary patent licenses occur both when the law decides whether a patent exists at all and when the law defines the reach of a patent. Take the latter first. Every patent concludes with one or more claims. Each claim comprises a single sentence that precisely states the exclusive right that the patent conveys. ${ }^{165}$ The idea here is the very opposite of ambiguity: the Patent Act requires claims because the patentee and the public both need to know precisely where the patent rights begin and end. ${ }^{166}$ Unfortunately, in practice the task of claim construction is rife with ambiguity. First, reducing a technological concept to words is a chancy thing; the available terminology may fail to capture the true nature of the innovation. ${ }^{167}$ Second, courts interpret claims based not on their plain English meaning, but on the meaning they would have to a person having ordinary skill in the art (a "PHOSITA")-i.e., the typical worker in the relevant field. ${ }^{168}$ Such a

164. RTMARK Projects, Product Disadvertisements in TV and Movies, http://www.rtmark.com/projects/app/disp (last visited June 7, 2006) (suggesting funding for "product displacement" portrayals in which "[t]he FedEx package arrives late and mangled" or "someone throws up after eating at McDonald's").

165. 35 U.S.C. $\S 112$.

166. Festo Corp. v. Shoketsu Kinzoku Kogyo Kabushiki Co., 535 U.S. 722,731 (2002). 167. Id. at 731 .

168. Phillips v. AWH Corp., 415 F.3d 1303, 1313 (Fed. Cir. 2005). 
perspective can be difficult to tease out. Third, even if the wording manages to capture the invention and the PHOSITA's interpretation is clear, patent's doctrine of equivalents allows a patent owner to reach beyond the literal boundaries of a claim to recover from those whose invention operates substantially the same way to achieve the same result. ${ }^{169}$ Like copyright's fair use doctrine and substantial similarity standard, the doctrine of equivalents quite reasonably sacrifices bright-line precision for flexibility and fairness. ${ }^{170}$ But in combination with the challenges of terminology and PHOSITA perspective, it frequently makes the reach of patent entitlements inherently ambiguous. ${ }^{171}$

Ambiguity is also found in the threshold determination of whether a given invention is patentable. The Patent Act grants its protection only to inventions that are novel, useful, and nonobvious. ${ }^{172}$ Of the various sources of indeterminacy in this inquiry, the one of interest here is nonobviousness, which is widely acknowledged as the most frequent basis for invalidation of patents ${ }^{173}$-and which, as we will soon see, is the factor that invites licensing information into the picture.

The question in nonobviousness analysis is whether the innovation would have been obvious to a PHOSITA given the state of the art at the time of invention. ${ }^{174}$ The primary focus is therefore the content of the prior art, the differences between the prior art and the claims at issue, and the level of ordinary skill in the relevant art. ${ }^{175}$ The Supreme Court has indicated, however, that secondary considerations such as the invention's commercial success may also be relevant to whether the invention was indeed obvious. ${ }^{176}$ Such considerations are helpful because they tend to be less technical than inquiries into prior art and are also less susceptible to hindsight bias (an invention naturally seems more obvious after it has been invented). ${ }^{177}$

The role of secondary considerations is not entirely clear. The Supreme Court has merely held that they "might" be relevant, ${ }^{178}$ and has subsequently implied that they cannot save a patent that otherwise appears obvious under the three explicit statutory factors. ${ }^{179}$ Yet the Federal Circuit has expressly elevated their importance, requiring their examination in all cases, ${ }^{180}$ observing that they

169. Graver Tank \& Mfg. Co. v. Linde Air Products Co., 339 U.S. 605, 608 (1950).

170. Festo, 535 U.S. at 731-33.

171. See R. Polk Wagner \& Lee Petherbridge, Is the Federal Circuit Succeeding? An Empirical Assessment of Judicial Performance, 152 U. PenN. L. ReV. 1105 (2004) (finding inconsistency in claim construction); Christian A. Chu, Empirical Analysis of the Federal Circuit's Claim Construction Trends, 16 BERKELEY TECH. L.J. 1075 (2001) (same).

172. 35 U.S.C. §§ 101 (useful), 102 (novel), 103 (nonobvious).

173. John R. Allison \& Mark A. Lemley, Empirical Evidence on the Validity of Litigated Patents, 26 AIPLA Q.J. 185, 208 (1998).

174. 35 U.S.C. $\S 103(a)$.

175. Graham v. John Deere Co. of Kansas City, 383 U.S. 1, 17 (1966).

176. Id. at $17-18$.

177. Id. at $35-36$.

178. Id. at 17-18.

179. Sakraida v. Ag Pro, Inc., 425 U.S. 273, 282-83 (1976); Dann v. Johnston, 425 U.S. 219, 230 n.4 (1976).

180. Stratoflex, Inc. v. Aeroquip Corp., 713 F.2d 1530, 1538 (Fed. Cir. 1983); In re 
"may often be the most probative and cogent evidence in the record," 181 and using them to rescue patents that were "otherwise doubtful." 182

The nonobviousness analysis and the secondary considerations that inform it are important for our purposes because one of those considerations is whether the patent owner has successfully licensed the invention to others in the industry. If so, the argument goes, they must view the patent as valid; otherwise, they would make use of the innovation without bothering to seek a license. And if those in the industry respect the patent's validity, how can a court conclude that it would have been obvious to a PHOSITA? ${ }^{183}$

By now, the flaws in this reasoning and its potential for accretive feedback should be apparent. We have already seen that parties often agree to pay for copyright and trademark licenses even if they sincerely doubt that they are infringing. The same is true in patent. Patent infringement litigation is notoriously costly, ranging from two to five times as expensive as copyright and trademark suits with similar amounts at stake. ${ }^{184}$ Moreover, like copyright and trademark, patent has traditionally been a property-rule regime, with supracompensatory damages and injunctions readily available to the prevailing rightsholder. ${ }^{185}$ This means that parties on the fringes of infringement will often agree to license even if the reach of the claims or merits of the patent are in doubt. The alternative is to take the chance of costly litigation, an adverse judgment, damages in excess of what a license would have cost, and particularly the disproportionate leverage that an injunction gives the rightsholder-a threatening prospect, particularly when the patented technology constitutes but one small component of the infringing product. Defendants with substantial investments already committed are unlikely take that chance; they will tend instead toward risk aversion. ${ }^{186}$

Yet despite these similarities to copyright and trademark licensing, doctrinal feedback in patent law exists only in a very limited form and does not lead to a systemic expansion of patent's reach. This lack of accretive growth results from two factors. First, any feedback from licensing information affects only the particular patent being litigated. The fact that a risk-averse party may have secured an unneeded license for Patent $X$ may make it easier for the owner of

Sernaker, 702 F.2d 989, 996 (Fed. Cir. 1983).

181. Stratoflex, 713 F.2d at 1538; accord Ashland Oil, Inc. v. Delta Resins \& Refractories, Inc., 776 F.2d 281, 306 (Fed. Cir. 1985).

182. Sernaker, 702 F.2d at 996; accord Stratoflex, 713 F.2d at 1538.

183. See, e.g., WMS Gaming, Inc. v. Int'l Game Tech., 184 F.3d 1339, 1359-60 (Fed. Cir. 1999) (citing licensing as evidence of "industry respect").

184. Am. Intellectual Prop. Law Ass’n, Report of the 2005 Economic Survey 22 (2005).

185. 35 U.S.C. $§ 284$ (allowing treble damages); W.L. Gore \& Assocs. v. Garlock, Inc., 842 F.2d 1275, 1281 (Fed. Cir. 1988) (favoring injunctions). A recent Supreme Court ruling has, however, cast doubt on how easily injunctions will issue. See infra notes 231-232 and accompanying text (discussing eBay Inc. v. MercExchange, L.L.C., 126 S. Ct. 1837 (2006)).

186. See Robert P. Merges, Commercial Success and Patent Standards: Economic Perspectives on Innovation, 76 CAL. L. REV. 803, 867-68 \& n.260 (1988) (noting that risk aversion may cause patent user to agree to pay more for license than an objective cost/benefit analysis would suggest). 
Patent $X$ to stave off an obviousness finding, but it has no effect on whether some unrelated Patent $Y$ is adjudged valid. Doctrinal feedback in patent law will therefore not expand the reach of the patent entitlement in general. In contrast, if the owner of a copyright in a photograph succeeds in convincing documentarians to seek a license before using the photo in their films, that licensing market is relevant to every subsequent fair use dispute between photographers and filmmakers, and accordingly has an accretive effect on the overall reach of copyright rights.

Second, and more important for our purposes, courts adjudicating patent disputes routinely recognize and account for the possibility that licensing means something other than respect for a patent's validity. Even those cases that attach primary importance to secondary considerations require the plaintiff to prove a nexus between the licensing evidence and the merits of the claimed invention; ${ }^{187}$ courts understand that patent users might prefer to license rather than litigate even a dubious patent, and that patent owners too might opt for a token fee instead of a lawsuit in which their patent could be invalidated. ${ }^{188}$ As we will now see, those who view accretive expansion as something to be avoided can import this heightened scrutiny into copyright and trademark law and thus shortcircuit their feedback loops, just as patent already short-circuits its own.

\section{NORMATIVE IMPLICATIONS}

\section{A. Do We Care?}

To this point, I have merely described the feedback phenomenon and the effects that it has on the reach of intellectual property entitlements. I will now turn to the normative questions: do we care? Is accretive expansion of intellectual property rights a problem? If so, what are the possible solutions?

At first blush, one might be tempted to view doctrinal feedback as benign. Why would one object to markets that form from voluntary transactions or to legal doctrines that measure liability by reference to industry practice? As already noted, commentators from otherwise incompatible camps agree that copyright's fair use doctrine should refer to such practices when defining the reach of the entitlement. ${ }^{189}$ Even among independent documentary filmmakers-a community that seems much more likely to be victim than victor in the permissions wars-there is appreciable support for a pro-licensing norm. ${ }^{190}$ Likewise, trademark's consumer confusion standard enjoys widespread acceptance, even if courts do occasionally give it too broad an interpretation. If these reasonable doctrines combine with voluntary exchanges

187. E.g., Ashland Oil, Inc. v. Delta Resins \& Refractories, Inc., 776 F.2d 281, 305-06 \& n.4 (Fed. Cir. 1985); Simmons Fastener Corp. v. Ill. Tool Works, Inc., 739 F.2d 1573, 1575 (Fed. Cir. 1984); Stratoflex, Inc. v. Aeroquip Corp., 713 F.2d 1530, 1539 (Fed. Cir. 1983).

188. I am indebted to Kristen Osenga for pointing out this risk aversion on patent owners' part.

189. See supra notes 53-59 and accompanying text.

190. AUFDERHEIDE \& JASZI, supra note 28, at 22-25. 
in the free market to produce an expansion of intellectual property rights, perhaps that means that rights should expand.

No matter what one's perspective on intellectual property, however, viewing doctrinal feedback in this way is overly simplistic. Take the economic approach to intellectual property law, which we might expect to be particularly deferential to licensing markets. A licensing culture that results from risk aversion on the part of the licensee and invites strategic holdout on the part of the licensor is unlikely to promote overall social welfare, even if the licensing motivations are economically rational from the individual parties' standpoint. ${ }^{191}$ A market formed in the shadow of legal ambiguities, risk-averse actors, and strategic bargaining thus tells us little about the entitlement's optimal coverage. Moreover, because intellectual property goods are nonrival, exclusive rights are not necessary to ensure that the goods gravitate to their most valuable use; instead, exclusive rights merely to provide an incentive to produce the goods in the first place. ${ }^{192}$ On that point, it is doubtful that the marginal, gray-area licensing that causes doctrinal feedback has a significant incentivizing effect; trademark owners have a considerable incentive to produce and popularize their marks for source-identification purposes alone, and the incidental uses that fall within fair use's gray area are unlikely to represent a primary revenue stream for copyright owners. Finally, even if licensing fees are important for incentive purposes, the economic approach must recognize that information is both an input and an output in the creative process. ${ }^{193}$ Thus the more licenses an artist needs to produce a new work, the more likely he or she is to abandon the enterprise entirely. ${ }^{194}$ The aggregate effect of a licensing culture may therefore be an anticommons, with the incentive to produce newer works unduly sacrificed at the altar of rewarding older works.

For those who view intellectual property as something other than a servant of market efficiency, the analysis is different but the outcome is the same. In copyright, for example, Wendy Gordon has argued that sometimes "the criteria that perfect markets maximize are simply not the criteria of most importance."195 And numerous commentators have observed that trademarks frequently assume a role in popular rhetoric that has little to do with the cost-lowering, sourceidentifying function for which the law provides protection. ${ }^{196}$

191. Cf. Gordon, Excuse, supra note 56, at 167 ("Assuming the goal of copyright is to achieve maximum social benefit, there is no reason to require a potential user of a work to ask the copyright owner's permission unless there is some way to believe the owner's self-interest is aligned with society's.").

192. William M. Landes \& Richard A. Posner, The Economic Structure of INTELLECTUAL PROPERTY LAW 12-14 (2003). Some commentators have argued that intellectual property rights not only incentivize creation but also prevent harmful overuse. E.g., id. at 22228. Mark Lemley cogently refutes this argument in Ex Ante Versus Ex Post Justifications for Intellectual Property, 71 U. CHI. L. REV. 129 (2004).

193. James Gibson, Re-Reifying Data, 80 Notre Dame L. ReV. 163, 212 (2004).

194. See, e.g., LESSIG, supra note 12, at 100-04.

195. Gordon, Excuse, supra note 56, at 161. One example is using excerpts of a work to criticize it. $I d$. at 157.

196. E.g., Rochelle Cooper Dreyfuss, Expressive Genericity: Trademarks as Language in 
From this standpoint, doctrinal feedback is particularly worrisome because (as we have already seen) it tends to be most prevalent when mere granules of intellectual property appear in transformative works of expression. When filmmakers, writers, and other artists avoid using some of our most meaningful cultural referents for fear of being sued, culture suffers. The effect, like the effect of doctrinal feedback itself, accretes incrementally and in varied contexts, but is no less real. Its aggregate impact on creativity may defy empirical measurement, but examples abound. A book focusing on an early twentiethcentury composer was withdrawn from circulation because less than one percent of its content comprised the composer's unpublished work and commentary thereon, and the owner of the composer's copyright disliked the book's critical take on its subject. ${ }^{197}$ During the filming of the dancing documentary Mad Hot Ballroom, someone spontaneously yelled three words-"Everybody dance now!"-from a popular song. The filmmakers had to edit the line out, despite its obvious appeal, because the song's copyright owner demanded $\$ 5,000$ for a license. ${ }^{198}$ Reticence to use trademarks without a license is equally evident. The writer and director of the hit animated film The Incredibles wanted to name his bomb-throwing French villain "Bomb Pérignon," but fear of a lawsuit from champagne maker Dom Pérignon prompted a change to "Bomb Voyage."199 Artwork depicting a Barbie doll attacked by various household appliances led Mattel to file a trademark infringement suit, which the artist was able to win only after four years of pro bono representation by the ACLU. ${ }^{200}$

Product placement also has a troubling effect on the creative process, possibly because it involves payment to, rather than from, the mark user. As the practice has become more prevalent and profitable, even its promoters have come to fear that financial temptation will unduly influence filmmakers' creativity. ${ }^{201}$ Of course, product placement is voluntary, so the market may sufficiently regulate its trade-off between financing and creativity: those in the industry who are willing to compromise creative choice to secure better financing will do so, those who aren't won't, and audiences can vote with their wallets as to which product they prefer. The problem, however, is that the increasing prevalence of product placement and prophylactic licensing threatens to extend trademark's reach such that there will be no second option; those

\footnotetext{
the Pepsi Generation, 65 Notre Dame L. Rev. 397 (1990); Alex Kozinski, Trademarks Unplugged, 68 N.Y.U. L. REv. 960, 972-75 (1993); Lemley, supra note 88, at 1696.

197. Richard Byrne, Silent Treatment, Chron. Higher Educ., July 16, 2004.

198. AOKI ET AL., supra note 28, at 14.

199. THE InCREDIBLES (Pixar 2004) (director's commentary on 2005 DVD).

200. HEINS \& BECKLES, supra note 24 , at $1 \&$ n.3.

201. On a scale of one to seven, where one is "strongly disagree" and seven is "strongly agree," members of the industry's leading product placement group averaged a 6.04 in response to this statement: "Placements can lead to trade-offs between the financial and creative sides of movie making." James Karrh et al., Practitioners' Evolving Views on Product Placement Effectiveness, 43 J. ADVERTISING RESEARCH 138, 145 (2003); see also Schieffelin \& Co. v. Jack Co. of Boca, Inc., 850 F. Supp. 232, 237 (S.D.N.Y. 1994) (noting that makers of Dom Pérignon champagne require script approval and on-the-set monitoring of how product is presented in James Bond movies and other films).
} 
filmmakers who prefer to preserve creative freedom and engage in unlicensed use of real-world brands will not be able to do so because the law will require a license.

Finally, regardless of whether one takes an economic or non-economic approach to intellectual property law, expansion by accretion raises the question of how paternalistic the law should be. One might favor an expansion of intellectual property entitlements but still want that expansion to be driven by top-down positivist sources rather than bottom-up licensing practices. ${ }^{202}$ The usual argument in favor of bottom-up regimes is that they reflect social values more directly than statutes and court rulings; with regard to fair use, for example, community practice supposedly represents "an understanding [that] may have been developed with an eye to the broader question" of copyright's goals. ${ }^{203}$ Given the amount of unnecessary licensing that takes place in the real world of intellectual property, however, this gives the process too much credit. It is less purposeful and more accretive than that. Licensing regimes and other community standards are not static, and they do not spring fully formed from the head of the god Equity. They develop and change over time, informed by legal and social norms, in a process that does not necessarily involve any conscious policy choice or reflect an optimal outcome. The law is thus not simply the public's scrivener. It should lead as well as follow, inform as well as react.

All told, then, there is reason to believe that expansion by accretion is not a good thing. The more meaningful question, however, is not whether this inadvertent expansion represents the best of all possible worlds, but whether its various solutions create greater problems than they cure. The following discussion therefore reviews the ways in which we could deal with doctrinal feedback and discusses their collateral effects. We will see that many of the solutions are surprisingly counterintuitive (e.g., increasing the complexity of intellectual property statutes or encouraging more litigation), and almost all come laden with normative implications that make them attractive only to those with certain views. In the end, however, I propose a more normatively neutral solution that comprises refinements in how the positive law scrutinizes licensing information and consumer motivation without requiring any great doctrinal leap.

\section{B. Reducing Uncertainty}

If those who use trademarks and copyrighted works can more accurately predict which uses are within the rightsholders' control, they will agree to fewer unneeded licenses. Clarifying the gray areas in the law is therefore one obvious option for those interested in curtailing the accretive expansion that doctrinal feedback produces. Of course, we may agree that clearer rules are needed, but disagree about whether those clear rules should limit entitlements or enlarge

202. Cf. Dogan \& Lemley, supra note 111, at 487 ("The real underlying issue is whether the trademark law should act here as a creator or as a reflector of societal norms.").

203. Weinreb, supra note 57, at 1152; accord Fisher, supra note 27, at 1680-81 \& n.100; Madison, supra note 59. 
them. That issue is for the most part outside the scope of this article. I will point out when a particular solution inherently favors the rightsholder over the user, or vice versa, but my overall purpose here is to identify the tools that policymakers can use to forestall doctrinal feedback, not to prescribe what to do with them.

1. Statutory Standards and Regulatory Rules

One obvious way to clarify intellectual property's ambiguities-whether they originate in code or case law-is to write more specific rules into the governing statutes. In other words, we can rid intellectual property law of ambiguities, and thus curtail doctrinal feedback, by moving from standards to rules.

The rules-versus-standards debate is an old one, in intellectual property and elsewhere. Broadly speaking, rules specify ex ante what conduct is forbidden, with only factual determinations remaining ex post: "Do not drive over fifty-five miles per hour." Standards set forth a more general admonition, leaving specific interpretation thereof for later adjudication: "Do not drive at unreasonable speeds." ${ }^{204}$ Standards provide less ex ante guidance, thus shifting more risk to those who operate near their boundaries, but provide more ex post flexibility in the individual case. ${ }^{205}$

In copyright, the doctrines that produce accretive expansion-the idea/expression dichotomy, the substantial similarity test, and the fair use defense-are all standards. ${ }^{206}$ Replacing or supplementing them with more specific rules would help retard the accretive expansion that doctrinal feedback produces. This would not require an abrupt change in direction; copyright has been steadily moving from standards to rules for some time. Indeed, the history of American copyright is essentially an evolution from a broad, industry-neutral property right to a set of detailed, industry-specific regulations. ${ }^{207}$ For example, the fair use standard has seen its universality and flexibility become less important as parties who would otherwise rely heavily on the doctrine-e.g., libraries, archivists, and educators-have increasingly operated under safeharbor statutes designed specifically for them. ${ }^{208}$

Arguing for more regulatory complexity, however, goes against the weight of copyright scholarship, which almost unanimously sees increased regulation as a tool of rent-seeking industries pursuing a positivist expansion of entitlements. ${ }^{209}$ While this may be true, we have now seen that a less complex

204. Louis Kaplow, Rules Versus Standards: An Economic Analysis, 42 DukE L.J. 557, 559-60 (1992); Cass R. Sunstein, Problems With Rules, 83 CAL. L. REV. 953, 959 (1995).

205. Kaplow, supra note 204, at 605 ("Because individuals tend to be less well informed concerning standards, they may bear more risk under standards than under rules .....").

206. See supra Part I.A.

207. See Joseph P. Liu, Regulatory Copyright, 83 N.C. L. REV. 87 (2004).

208. E.g., 17 U.S.C. $\S \S 108,110(1)-(2), 112(f)$.

209. E.g., Dan L. Burk \& Mark A. Lemley, Policy Levers in Patent Law, 89 VA. L. Rev. 1575, 1637-38 (2003); Denicola, supra note 88, at 1685-86; Jessica D. Litman, Copyright, 
standards-based regime carries with it its own expansive risk-more subtle, perhaps, but no less threatening. In fact, expansion by accretion may be more threatening, in that by the time it occurs it is so ingrained in industry practice that reversing it may prove impossible. Contrary to the conventional wisdom, then, a balkanized, industry-specific code may be a help, not a hindrance, in halting the expansion of intellectual property rights.

For example, suppose we supplement fair use with a rule that no license is required for any excerpt of fewer than $X$ words, or $X$ seconds of recorded music. Such a rule may strike academics as simplistic to the point of idiocy, but if realworld lawyers can't give advice to mass-market clients at levels significantly more sophisticated than that, the current more nuanced standard is no better (and carries with it the added potential for doctrinal feedback). On the other hand, any bright-line rule comes with its own problems. The actual number we use for $X$ may be less important than the clarity the rule would provide, but the number still matters, and would be another battleground in the war over how to balance private incentive and public benefit. If we choose, say, the number fifty, then Robert Frost's poem Fire And Ice (clocking in at fifty-one words) enjoys a protection that Ogden Nash's The Hippopotamus (forty-six) does not. If that seems unfair to Nash, we could change the rule so as not to apply to works that comprise less than fifty words. Even that rule, however, fails to recognize that the use of an entire work in an incidental manner, like a photo in the background of a film, may be a better fair use candidate than a fragmented but purposeful taking. We could again add caveats and variations to address that issue, but the more adjustments we make, the more the rule comes to resemble the indeterminate standard we were trying to replace.

These objections to bright-line rules for fair use would be less problematic if the rules were merely safe harbors, giving clarity to those who fall within their limits without denying others the right to fall back on the more general standard. ${ }^{210}$ Yet safe-harbor rules (and their close cousin, industry-specific "best practices" guidelines) have historically enjoyed mixed success at best. Promulgated in a number of copyright contexts, such approaches often end up compromising flexibility and adaptability without providing much clarity or

Compromise, and Legislative History, 72 CORNELL L. REV. 857, 870-79 (1987); Liu, supra note 207, at 134-39; Timothy Wu, Copyright's Communications Policy, 103 Mich. L. Rev. 278, 29192 (2004); see also Michael W. Carroll, One for All: The Problem of Uniformity Cost in Intellectual Property Law 60-62 (Villanova Sch. of Law Working Paper Series, Paper No. 41, 2005) (arguing that using standards rather than rules reduces copyright's uniformity costs). But see Shubha Ghosh, The Merits of Ownership; Or, How I Learned To Stop Worrying and Love Intellectual Property, 15 HARV. J.L. \& TECH. 453, 482 (2002) (arguing that "the family resemblance between intellectual property law and tax law need not be bemoaned").

210. See Liu, supra note 207, at 141 (noting that industry-specific regulations "do not preclude flexibility, insofar as courts remain free to craft additional exceptions through the fair use doctrine"); Matthew Sag, God in the Machine: A New Structural Analysis of Copyright's Fair Use Doctrine, 11 Mich. Telecomm. \& TeCH. L. ReV. 381 (2005) (arguing that ambiguity inherent in fair use "standard" is preferable to more determinative fair use "rule" because fair use must be as flexible and generally applicable to serve as counterbalance to broad, technologyneutral rights that copyright grants to authors). 
protection for users, as courts convert safe harbors into the only harbors and make floors into ceilings and minimums into maximums. ${ }^{211}$

In contrast to copyright, trademark law has largely avoided regulatory complexity, despite having seen its own positivist expansion in recent years. ${ }^{212}$ Using statutes to provide predictability for trademark users nevertheless presents significant challenges. Foremost among them is that trademark's doctrinal feedback is based on evolving consumer perceptions. Legislation alone cannot halt this evolution; a statute cannot simply order consumers to stop interpreting trademark practices in an expansive way. Here, however, the same dynamic that causes trademark's doctrinal feedback can cure it. If consumers learn from trademark practices that reflect expansive views of the entitlement's reach, they can learn from practices that reflect narrower views as well. The law can accordingly change consumer perception by changing the legal standards and practices that inform persuasion knowledge. For example, suppose Congress adopts a bright-line rule that permits all unlicensed uses of branded goods in movies. At first, such uses might result in confusion, as consumers accustomed to seeing only licensed uses infer some connection between the mark owner and the filmmaker. ${ }^{213}$ But over time, as consumers encounter more and more clearly unlicensed uses and see fewer and fewer blurred marks, they will adjust their perception to reflect the new licensing reality.

The question remains, however, whether such bright-line trademark rules should favor users or rightsholders. Converting trademark into a full-fledged property right would curtail feedback by severing doctrine from its moorings in consumer confusion. At the other extreme, eliminating dilution and sponsorship confusion altogether and requiring proof of confusion as to origin in every case would have much the same effect. More moderate revisions also present normative dilemmas. A single, clear statutory definition of sponsorship confusion would rid us of the vague hodgepodge of confusion variations (endorsement, association, connection, etc.) and modifiers (of any kind, in some way, etc.) that make ex ante evaluation of liability so difficult, and more guidance regarding use of survey evidence would help as well. But what's the "right" definition? What's the "correct" percentage of consumers who must be confused before a use is considered infringing? Can the federal government impose its answers to these questions on fifty different state trademark regimes? And would rightsholders have too much influence over the formulation of those answers, by virtue of their lobbying power?

In the end, then, one's normative policy preferences regarding the proper reach of intellectual property entitlements will largely determine one's attitude toward whether and how bright-line statutory amendments might limit doctrinal feedback. Those who welcome an expansion of entitlements but who prefer a

211. See HeInS \& BECKLES, supra note 24, at 6-7; Kenneth D. Crews, The Law of Fair Use and the Illusion of Fair-Use Guidelines, 62 Оніо Sт. L.J. 599 (2001).

212. See sources cited supra note 87.

213. As the Supreme Court recently held, preventing consumer confusion is not trademark's only priority; confusion is sometimes the price we pay to achieve other goals. KP Permanent Make-Up, Inc. v. Lasting Impression I, Inc., 543 U.S. 111, 121-22 (2004). 
top-down positivist policy over the accretive effect of licensing practice may favor clearer statutory rules. Those who object to further expansion will be less inclined to rely on a legislative process that has facilitated that expansion in the past. In both cases, however, the normative battle over what the rules should say may cause more trouble than curtailing doctrinal feedback is worth.

\section{Increased Adjudication}

In the foregoing discussion, the question of how best to resolve intellectual property's feedback-fueling ambiguities became a question of institutional competence: can the legislature clarify the relevant standards without making matters worse? Our inquiry is accordingly not complete without considering the ability of other institutions to provide clarity. The most obvious alternative is the judiciary, which has proved itself capable of industry-specific intellectual property regulation. ${ }^{214}$ Courts are a particularly attractive option for those who value flexible standards over bright-line rules and who view the legislative process as an invitation to rent-seeking that produces both regulatory complexity and poor policy results.

How might the judiciary clarify the ambiguities that cause doctrinal feedback? Two possibilities present themselves. The first involves explicit judicial rulemaking. In a number of instances, courts have recognized the frustrating indeterminacy of intellectual property's standards and have provided bright-line clarity. To pick one copyright example, the Sixth Circuit recently held that the ambiguous "substantial similarity" test is irrelevant in cases involving the sampling of recorded music. ${ }^{215}$ Recognizing that "it would appear to be cheaper to license than to litigate," the court decided to spare samplers the "mental, musicological, and technological gymnastics" that the vague standard requires and instead impose a bright-line rule favoring licensing. ${ }^{216}$ And in trademark law, the First Circuit realized that evidence of sponsorship confusion is essentially circular, in that consumer perception both informs and is informed by the law. ${ }^{217}$ It therefore did away with any need to show that "members of the public will actually conclude that defendants' product was officially sponsored" by the plaintiff. ${ }^{218}$

Relying on judges to clarify ambiguities requires both a broad view of judicial power and confidence in judicial policy judgments. In each of the two foregoing cases, for example, the court arguably crossed the line from interpretation to legislation and then reached a poor policy result. ${ }^{219}$ If curtailing

214. See Burk \& Lemley, supra note 209.

215. Bridgeport Music, Inc. v. Dimension Films, 410 F.3d 792 (6th Cir. 2005).

216. Id. at 803.

217. Boston Athletic Ass'n v. Sullivan, 867 F.2d 22, 33 (1st Cir. 1989).

218. Id.

219. In Bridgeport Music, the court took a statute that makes sound recording copyrights less extensive than other copyrights and somehow read it to make sound recording copyrights more extensive. In Boston Athletic, the court essentially jettisoned trademark's consumer confusion standard altogether, a holding with no basis in statute or common law. 
doctrinal feedback is important enough, perhaps this is the price we pay. If not, however, we may want to consider a second way in which courts can help clarify ambiguities. Recall that risk aversion and other pro-licensing influences in key industries mean that relatively few disputes over the reach of copyright and trademark entitlements ever make it to court. Indeed, even in the absence of risk aversion, disputants have a suboptimal incentive to litigate a rights-defining issue because they bear nearly all the costs of litigation but do not fully internalize the benefits; third parties gain valuable knowledge from reading the opinion and observing how the case was resolved, without contributing a dime toward litigation expenses. ${ }^{220}$ Combine this lack of litigation with the ambiguity of the doctrines that apply when a case actually is litigated and you have a remarkable dearth of helpful precedent on which copyright and trademark users can rely.

Courts therefore do not have to replace a vague standard with a bright-line rule in order to help curtail doctrinal feedback; rather, every ruling that applies the standard helps clarify it. This suggests that we should encourage more frequent rulings on the reach of intellectual property entitlements. That's right: we need more lawsuits. Allowing prevailing defendants to recover litigation costs from rightsholding plaintiffs might help-although if prevailing rightsholders can recover them too, users are not going to be much more likely to risk litigation than they are now. ${ }^{221}$ Public interest groups that now merely give advice to copyright and trademark users might focus their resources instead on litigating disputes. ${ }^{222}$ A federal small-claims court focusing on intellectual property could be empowered to issue substantive rulings. ${ }^{223}$ Or a government

220. If an issue is sufficiently important, those with an interest will not be content to sit idle and reap informational benefits but will band together to champion their preferred outcome. Public choice theory tells us that this is particularly true for highly organized communities or industries dominated by a few players because they are better positioned to internalize all of litigation's benefits. (The recording and movie industries' unanimity in the file-sharing wars comes to mind, e.g., Metro-Goldwyn-Mayer Studios Inc. v. Grokster, Ltd., 125 S. Ct. 2764 (2005), as does the prevalence of amicus briefs in groundbreaking cases.) But more often organizational costs will be too high or the issues too unexceptional. Some scholars have offered solutions to this dilemma in the patent realm. E.g., Joseph Farrell \& Robert P. Merges, Incentives To Challenge and Defend Patents: Why Litigation Won't Reliably Fix Patent Office Errors and Why Administrative Patent Review Might Help, 19 BERKELEY TECH. L.J. 943 (2004); Joseph Scott Miller, Building a Better Bounty: Litigation-Stage Rewards for Defeating Patents, 19 Berkeley TeCH. L.J. 667 (2004); Carl Shapiro, Patent System Reform: Economic Analysis and Critique, 19 BERKELEY TECH. L.J. 1017 (2004).

221. See Fogerty v. Fantasy, Inc., 510 U.S. 517, 527 (1994) (“[D]efendants who seek to advance a variety of meritorious copyright defenses should be encouraged to litigate them to the same extent that plaintiffs are encouraged to litigate meritorious claims of infringement.").

222. See Elaine Dutka, No Free Samples for Documentaries., N.Y. Times, May 28, 2006, $\S 2$, at 16 (discussing coalition of lawyers that donate fair-use advice to filmmakers); Fair Use Network, http://www.fairusenetwork.org (providing free advice on uses of intellectual property); cf. Anick Jesdanun, EFF Prefers Litigation to Legislation, SALON, July 4,2006, http://www.salon.com/wire/ap/D8ILDUDO0.html.

223. See Remedies for Small Copyright Claims: Hearing Before the Subcomm. on Courts, the Internet, and Intell. Prop. of the H. Comm. on the Judiciary, Mar. 29, 2006 (transcript available at http://commdocs.house.gov/committees/judiciary/hju26767.000/hju26767_0f.htm); 
agency might be authorized to issue opinions on particular disputes, in the style of SEC no-action letters or IRS advisories ${ }^{224}$-an attractive option when one considers that more litigation alone will do little good if cases settle or are resolved on procedural grounds. Of course, each of these mechanisms comes heavily laden with normative baggage. Public interest litigation, for example, is likely to promote pro-user policies, whereas recent Congressional interest in a small-claims court seems rooted in concern for copyright owners. ${ }^{225}$ Less apparent, but more important, is that an increase in the number of cases litigated will have an expansive effect. Courts are so diffuse and so rarely unanimous on gray-area issues that they almost invariably send mixed signals to the marketplace. (In trademark, the problem is particularly acute, because both federal and state law govern the reach of entitlements.) Therefore, unless the Supreme Court weighs in, potential licensees with an eye on the national market will look to the most conservative rulings, regardless of their source and regardless of whether they articulate new bright-line rules or merely apply existing standards. This means that the judiciary's fitness for reducing overall indeterminacy is largely in the eye of the beholder: those who favor expansive entitlements will embrace judicial clarification, and those who don't won't.

As promised, then, one's normative views on the reach of intellectual property entitlements will largely determine one's preferred method for clarifying copyright and trademark ambiguities, regardless of whether one chooses a statutory or adjudicative solution. Curing indeterminacy comes heavily laden with normative difficulties. In the next section, we will see that the same holds true when we attempt to curtail doctrinal feedback not by clarifying ambiguities, but by reducing the severity of the consequences that infringing parties face.

\section{Reducing Consequences}

Uncertainty regarding the reach of intellectual property entitlements is only one of the factors that give rise to unneeded licensing. An equally important factor is the penalty for infringement. Even in the face of considerable uncertainty, a risk-averse user would not hesitate to proceed unlicensed if a finding of infringement simply meant the payment of a fair-market licensing fee. In reality, however, the consequences are much more severe. Remedies in copyright cases include not only actual damages, but also statutory damages of up to $\$ 150,000$ per work infringed, disgorgement of profits, and attorney's fees. $^{226}$ Trademark defendants face similar consequences. ${ }^{227}$ Making supracompensatory damages unavailable or reducing their severity would

Mark A. Lemley \& R. Anthony Reese, A Quick and Inexpensive System for Resolving Peer-toPeer Copyright Disputes, 23 CARDOZO ARTS \& ENT. L.J. 1 (2005).

224. For this point I'm indebted to Mike Carroll and Shari Motro, each of whom independently suggested it.

225. See Remedies for Small Copyright Claims, supra note 223.

226. See sources cited supra note 18.

227. See sources cited supra notes 112-113. 
therefore decrease the likelihood that intellectual property users would secure an unneeded license, and would accordingly reduce doctrinal feedback even when entitlements remain indeterminate.

To some extent, copyright and trademark law already remove the threat of excessive money damages in cases of innocent infringement. ${ }^{228}$ The real sticking point, however, is not monetary remedies but injunctions, which can bring high-cost projects to a screeching halt when a rightsholder whose intellectual property appears in the work, however briefly, secures an order against its release. This presents a classic holdout problem, as the rightsholder demands payment greatly in excess of the value that its intellectual property represents to the new project. If the rightsholder could demand only a compensatory licensing fee, its ability to hijack the defendant's entire production process would disappear. Using some form of liability rule to govern copyright and trademark entitlements would therefore go a long way toward curtailing the unnecessary licensing that fuels doctrinal feedback. ${ }^{229}$

Although of more recent vintage than the rules-versus-standards battle, the property-rule-versus-liability-rule debate has been going on for some time in intellectual property scholarship. ${ }^{230}$ Recently the Supreme Court entered the debate as well; in eBay Inc. v. MercExchange, L.L.C., ${ }^{231}$ the Court rejected any presumption favoring injunctions in patent cases and suggested in dicta that such favoritism is also unwarranted in copyright. ${ }^{232}$ This newfound judicial sensitivity to the effect of injunctions suggests that mitigating the consequences of infringement is a politically realistic way to curtail accretive expansion.

One obvious place to start is with preliminary injunctions. Courts have traditionally found such injunctions appropriate "in the vast majority of cases"

228. E.g., 15 U.S.C. § 1114(2) (trademark); 17 U.S.C. §§ 405(b), 504(c)(2) (copyright).

229. The terms "liability rule" and "property rule" come from Guido Calabresi \& A. Douglas Melamed, Property Rules, Liability Rules, and Inalienability: One View of the Cathedral, 85 HARV. L. REV. 1089 (1972). "Whenever someone may destroy the initial entitlement if he is willing to pay an objectively determined value for it, an entitlement is protected by a liability rule." Id. at 1092 . "An entitlement is protected by a property rule to the extent that someone who wishes to remove the entitlement from its holder must buy it from him in a voluntary transaction in which the value of the entitlement is agreed upon by the seller." Id.

230. E.g., Benjamin Kaplan, An Unhurried View of Copyright 73-74 (1966); Ralph Brown, Civil Remedies for Intellectual Property Invasions: Themes and Variations, 55 L. \& ConTEMP. Probs. 45, 47-48 (1992); Gordon, Excuse, supra note 56, at 188-92; Alex Kozinski \& Christopher Newman, What's So Fair About Fair Use?, 46 J. COPYRIGHT Soc'y U.S.A. 513 (1999); Pierre Leval, Toward a Fair Use Standard, 103 HARV. L. REV. 1105, 1132-34 (1990).

231. 126 S. Ct. 1837 (2006). Even before MercExchange, the Court had hinted that lower courts should consider judge-made licenses. See New York Times Co. v. Tasini, 533 U.S. 483, 505 (2001); Campbell v. Acuff-Rose Music, Inc., 510 U.S. 569, 578 n.10 (1994); Dun v. Lumbermen's Credit Ass'n, 209 U.S. 20, 23-24 (1908). But see Harper \& Row Publishers, Inc. v. Nation Enters., 471 U.S. 539, 569 (1985) ("Congress has not designed, and we see no warrant for judicially imposing, a 'compulsory license' permitting unfettered access to the unpublished copyrighted expression of public figures.").

232. $126 \mathrm{~S}$. Ct. at 1840-41. In a concurring opinion, Justice Kennedy specifically cited the holdout problems that arise when injunctions give rightsholders "undue leverage in negotiations"-particularly if the entitlement covers "but a small component of the product the [defendants] seek to produce." Id. at 1842 (Kennedy, J., concurring). 
and issue them even absent proof of irreparable harm, as long as the rightsholder demonstrates a likelihood of success on the merits. ${ }^{233}$ Yet preliminary injunctions are particularly pernicious because they tend to stop defendants in their tracks and bring them to the bargaining table-thus both creating an early opportunity for holdout and keeping cases from reaching a substantive ruling that might clarify feedback-fueling gray areas. ${ }^{234}$ If we removed the categorical presumptions in favor of such injunctions, as MercExchange implies should be done, intellectual property users would be less likely to engage in gray-area licensing and more likely to risk litigation.

Even if preliminary injunctions were rarer, however, the specter of permanent injunctions and supracompensatory damages would cause many intellectual property users to embrace unneeded licenses. The scholarship has produced a number of liability-rule proposals that would mitigate this tendency. ${ }^{235}$ Yet whether such a rule is an attractive solution to doctrinal feedback depends on one's normative views on other important intellectual property questions.

For example, a liability rule might produce an increase in litigation over the reach of copyright and trademark entitlements: as the threat of injunction disappears, users become less risk averse and more willing to roll the liability dice. If so, this would curtail doctrinal feedback in two ways. First, it would create more opportunities for courts to issue substantive rulings, which would clarify the legal ambiguities that cause unneeded licensing. Second, it would mean that positive law, in the form of judicial decisions, would play a greater role in the valuation of entitlements, displacing the private licensing that fuels doctrinal feedback. Therefore, those who trust courts more than legislatures or markets when it comes to entitlement valuation might prefer this outcome-an obvious point, common to any liability rule. Less obvious is that court-imposed licensing would likely have its own expansive effect, because once courts no longer confront the all-or-nothing choice that a property rule imposes, they will be more inclined to "split the baby" and order moderate licensing fees in cases that the defendant would once have won outright. Any such expansion would be positivist, not accretive, but would still trouble those who oppose any growth in entitlements.

Another possibility is that a liability rule would actually increase the incidence of private licensing; parties sometimes transact more efficiently in the

233. Woods v. Universal City Studios, Inc., 920 F. Supp. 62,65 (S.D.N.Y. 1996) (copyright case); see also Int'1 Kennel Club of Chicago, Inc. v. Mighty Star, Inc., 846 F.2d 1079, 1084 (7th Cir. 1988) (trademark); Standard \& Poor's Corp. v. Commodity Exchange, Inc., 683 F.2d 704, 708 (2d Cir. 1982) (trademark).

234. Brown, supra note 230, at 47.

235. For example, when holdout is especially threatening (such as when the use is transformative), several commentators have suggested an accounting of profits as the sole copyright remedy. Gordon, Render, supra note 56, at 91; Kozinski \& Newman, supra note 230, at 526; Jed Rubenfeld, The Freedom of Imagination: Copyright's Constitutionality, 112 YALE L.J. 1, 55-58 (2002); John Tehranian, Whither Copyright? Transformative Use, Free Speech, and an Intermediate Liability Proposal, 2005 BYU L. REV. 1201, 1239-40. 
shadow of liability rules, not less. ${ }^{236}$ Getting rid of injunctions might make rightsholders more willing to offer attractive licensing terms rather than confront the uncertainty of court-ordered royalties. ${ }^{237}$ If so, those who already engage in prophylactic licensing might continue to do so, happy to pay less than they do now. Those who cannot currently afford to license, and who must instead alter or abandon their projects, might see licensing fees become more affordable. Courts would still look to these licenses when determining whether a given use is fair, and consumers would still infer sponsorship vel non from the trademark practices they encounter.

Whether this outcome is attractive depends on how accurately the new and improved licensing market correlates with overall social welfare. The market would certainly be more representative of true arms-length bargains between equals. But holdout and risk aversion are only some of the inefficiencies that intellectual property confronts. Another is positive externalities: the kinds of works at the core of the feedback problem-movies, music, etc.-produce broad social benefits that neither party internalizes and that are accordingly not captured even in more efficient bargaining. ${ }^{238}$ Those who consider these externalities significant will therefore approve of a liability-rule regime only if it discounts monetary damages to account for these hidden values (e.g., by expressly allowing for wholly uncompensated uses of copyrights and trademarks). ${ }^{239}$ If courts instead take a one-size-fits-all approach-charging a penurious documentarian the same fee as a major movie studio just because they both use the same material-then the game may not be worth the candle.

What this all tells us is that no matter what the effect of a liability rule-more litigation, more licensing, or both-its appeal depends on one's normative views on other topics, just as we saw with previous solutions to doctrinal feedback, and the appeal will be greatest to those who favor expansion or discount externalities. The search for a more normatively neutral solution continues.

\section{Doctrinal Refinements}

We have now seen that clarifying legal ambiguities and reducing the consequences of infringement can go a long way toward curtailing doctrinal feedback. Both approaches, however, carry costs that may be unacceptably high, depending on one's normative views on other important intellectual property issues. Moreover, both focus on reducing risk and thus would have no effect on the symbiotic licensing markets that can also fuel the feedback loop. This final section will therefore discuss how changes in copyright and trademark that do not address risk aversion can nevertheless help address the feedback problem, and do so in a more normatively neutral way.

236. See IAn Ayres, Optional Law 142-65 (2005).

237. See Kozinski \& Newman, supra note 230, at 527.

238. See Gordon, Excuse, supra note 56, at 176-77; Loren, supra note 64, at 6; Africa, supra note 26, at 1166.

239. E.g., Gordon, Render, supra note 56, at $90 \&$ n.59. 
The most obvious candidates for revision are those doctrines that refer to licensing markets: the "market effect" factor in copyright's fair use defense and trademark's "consumer confusion" cynosure. As already discussed, however, these doctrines enjoy widespread acceptance, and for good reason. Rather than discarding them entirely, then, we should explore ways of making them more attentive to the danger of doctrinal feedback. We want intellectual property entitlements to be market-referential without being market-reverential.

Here we can take a cue from patent law, which manages to refer to licensing markets without producing accretive expansion. Part of the reason that patent law is able to pull this off is that its case law explicitly infuses courts with a healthy skepticism towards the significance of licensing evidence. ${ }^{240}$ The cases reveal a longstanding practice of discounting licensing information when the fees are suspiciously low, the licensing agreement gives the licensee things of value besides than the patented technology, or the rightsholder's market penetration is unproven. ${ }^{241}$ Patent courts know that such licensing often indicates not tacit acceptance of a patent's validity, but a starkly practical cost/benefit judgment that it is better to license than litigate.

The lesson for copyright is clear. If fair use jurisprudence were to focus not just on whether a licensing market exists, but on why a licensing market exists, its reliance on private transactions as a proxy for public welfare would make more sense. When licenses are the result of uncertainty as to how far the right extends and fear that an expensive project could be held up because of one small component, the licenses are not particularly meaningful and other fair use factors should carry more weight. In contrast, when liability is clear and the user adds little value (as when an entire work is taken and used in a nontransformative way), licensing markets should play an important role in the analysis. This jurisprudential change requires no great doctrinal leap; courts already recognize that a single defendant's request for a license is irrelevant when the request goes unfulfilled and the defendant subsequently invokes fair use. ${ }^{242}$ All that remains is for courts (or Congress) to extrapolate beyond the individual defendant's case and realize that even when an entire community habitually seeks licenses, the resulting market is not always the best measure of

240. See sources cited supra note 187.

241. E.g., John E. Thropp's Sons' Co. v. Seiberling, 264 U.S. 320, 330 (1924); Rockwell Int'l Corp. v. U.S., 37 Fed. Cl. 478, 501 (1997); EWP Corp. v. Reliance Universal Inc., 755 F.2d 898, 907-08 (Fed. Cir. 1985); Stratoflex, Inc. v. Aeroquip Corp., 713 F.2d 1530, 1539 (Fed. Cir. 1983); Kleinman v. Kobler, 230 F.2d 913, 914 (2d Cir. 1956); N. Elec. Co. v. U.S., 386 F.2d 845, 849 (Ct. Cl. 1967); see also Merges, supra note 186, at 829 ("Where a licensee has other motivations-especially a desire to avoid litigation, or a need to license a package of technology including the patent at issue-licenses have not been as effective in establishing patentability."); Eric von Hippel, Appropriability of Innovation Benefit as a Predictor of the Source of Innovation, 11 RES. POL'Y 95, 102 n.9 (1982) (concluding that ambiguity as to validity and reach of patent rights results in licensing fees determined "at least as much by the contenders' relative willingness to pay to avoid the expense and bother of a court fight as it is by the merits of the particular case").

242. E.g., Campbell v. Acuff-Rose Music, Inc., 510 U.S. 569, 585 n.18 (1994); Bill Graham Archives v. Dorling Kindersley Ltd., 448 F.3d 605, 615 (2d Cir. 2006). 
the entitlement's optimal reach. ${ }^{243}$

Patent's approach might not work as well for trademark law. There are some parallels: if courts engaged in a more penetrating inquiry into trademark licensing, they would undoubtedly discover that users often secure licenses to avoid any risk of litigation or because they receive something other than immunity from liability (e.g., product placement financing), rather than because the law favors the rightsholder. But except in its most expansive property-right incarnation, trademark law focuses not on the rightsholder's interests, but on consumer perception. And if consumers expect a given use to be licensed, the motivation for the licensing practices that formed that expectation seems normatively irrelevant. Confusion is confusion, and demands a remedy. For the same reason, the liability rules discussed above are poor solutions to trademark feedback. A liability rule would not remedy confusion; it would merely compensate the mark owner for confusion's effects.

Yet if we focus on motivation of a different sort, we can escape this conundrum. Instead of inquiring into licensing motivation, courts could inquire into consumer motivation: does the confusion actually make a difference to consumers? In the classic "passing off" trademark case, we can safely presume that confusion is material because marks are one of consumers' primary means of distinguishing between products. But in cases involving sponsorship, approval, and especially permission, the mark's materiality to the purchasing decision is less apparent. No one watches the Olympics simply because Xerox happens to be the sponsor. And chances are that few people select the movies they see or television programs they watch based on what products appear in them, even if they assume that the appearances are licensed. ${ }^{244}$ Mark owners should therefore have to show not only that unlicensed uses are confusing, but also that that confusion is material to consumers' economic choices. ${ }^{245}$

As with copyright, this doctrinal revision works no great change in the law. Several of the narrower merchandising cases rested their holdings on the proposition that consumers didn't care whether the merchandise they purchased was "official," even if they were confused as to whether it was. ${ }^{246}$ And in a

243. Three court opinions have already flirted with this approach, although two (from the same case) lack precedential value. See Bill Graham Archives v. Dorling Kindersley Ltd., 448 F.3d 605, 614-15 (2d Cir. 2006) (holding that copyright owner cannot prevent transformative fair use through strategic licensing or by pointing to certain users' willingness to license); Princeton Univ. Press v. Mich. Document Servs., Inc., 99 F.3d 1381, 1397 (6th Cir. 1996) (en banc) (Merritt, J., dissenting) ("If the publishers have no right to the fee in many of the instances in which they are collecting it, we should not validate that practice by now using the income derived from it to justify further imposition of fees."); Princeton Univ. Press v. Mich. Document Servs., Inc., No. 94-1778, 1996 WL 54741, at*11 (6th Cir. Feb. 12, 1996) (dismissing evidence of lost "permission fees" because "[t]he right to permission fees is precisely what is at issue here"), vacated, 74 F.3d 1512 (6th Cir. 1996).

244. See Lemley, supra note 88, at 1707 (recognizing distinction between consumers who are not confused "about the relationship between the two products, but nonetheless believe that the defendant might have needed a license to use the mark"); accord Dogan \& Lemley, supra note 111 , at 486 n.101.

245. See Lunney, supra note 88, at 397-98.

246. Int'l Order of Job's Daughters v. Lindeburg and Co., 633 F.2d 912, 918 (9th Cir. 
recent case challenging the unlicensed use of a mark in a movie, the mark owner failed to secure a preliminary injunction partly because the court didn't believe that the appearance of the mark would influence the public's desire to see the film. ${ }^{247}$ Requiring mark owners to prove this additional element will obviously make proving infringement harder, but courts and Congress remain free to oversee an enlargement of trademark entitlements through dilution theory and the continued viability of broad sponsorship confusion liability.

In the end, then, encouraging a more penetrating inquiry into the motivations of copyright licensees and confused consumers may be the least normatively intrusive way to curtail doctrinal feedback and the accretive expansion it causes. No change in the law is entirely normatively neutral, of course, and all the solutions we have considered obviously share the normative judgment that accretive expansion is a problem. But the other alternatives, although effective, have more serious normative consequences. That said, those who do not fear or mind rent-seeking may prefer the adoption of statutes featuring industry-specific, bright-line rules. Those for whom expansion of intellectual property rights is less of a problem than ambiguous standards may favor encouraging more litigation. Those who believe that holdout and risk aversion are all that stand in the way of optimal allocation of intellectual property entitlements might want to promote bargaining in the shadow of liability rules. In all these cases, the positive law becomes a more active steward of intellectual property policy.

\section{CONCLUSION}

Doctrinal feedback subtly rigs the intellectual property game in favor of rightsholders. In copyright, it is pronounced, pernicious, and pervasive, causing an accretive expansion largely unnoticed in positive law and unappreciated in the scholarship. In trademark, it is more attenuated and limited in effect, but nevertheless threatens to extend rightsholder control in surprising and worrisome ways. In patent, it is muted and causes no systemic growth in entitlements. ${ }^{248}$

1980); Board of Governors of the University of North Carolina v. Helpingstine, 714 F. Supp. 167, 173 (M.D.N.C. 1989); University of Pittsburgh v. Champion Products, Inc., 566 F. Supp. 711, 720-21 (W.D. Pa. 1983). But see Warner Bros., Inc. v. Gay Toys, Inc., 724 F.2d 327, 332 (2d Cir. 1983) (discounting evidence that consumers did not care about perceived association between defendant's product and mark owner).

247. Caterpillar Inc. v. Walt Disney Co., 287 F. Supp. 2d 913, 920 (C.D. Ill. 2003).

248. Although it is outside the scope of this article, I should point out the feedback potential in other areas of the law, particularly those whose doctrines incorporate that famous legal fiction and invitation to circularity, "reasonableness." Examples include eminent domain's "reasonable, investment-backed expectations," see Lucas v. S.C. Coastal Council, 505 U.S. 1003, 1034 (1992) (Kennedy, J., concurring) ("[I]f the owner's reasonable expectations are shaped by what courts allow as a proper exercise of governmental authority, property tends to become what the courts say it is."), the Fourth Amendment's "reasonable expectations of privacy," see United States v. White, 401 U.S. 745, 786 (Harlan, J., dissenting) ("Our expectations, and the risks we assume, are in large part reflections of laws that translate into rules the customs and values of the past and present."), and tort law's "reasonable person"-a standard that may cause risk-averse 
No matter what one's view on the propriety of expanded intellectual property rights, the feedback effect is problematic. Yet when it comes to crafting a solution, one's views matter a great deal, because the most obvious cures come laden with normative baggage. One solution, however, promises to remain (mostly) normatively neutral and requires no great doctrinal leap: subtle refinements in how the positive law scrutinizes licensing information and consumer motivation.

In the end, there is no panacea for the phenomenon of doctrinal feedback, but we can start by promoting awareness of the ways in which risk aversion and other pro-licensing factors distort the informational content of the markets on which the law relies. Such awareness will do nothing to halt the positivist expansion that troubles so many intellectual property observers, but it will help ensure that any expansion in the reach of intellectual property entitlements is the result of conscious policy choice and democratic process, not inadvertent accretion.

manufacturers to use product warnings that at first appear absurd but whose ubiquity eventually causes the public to lower its own estimation of reasonableness, $c f$. Jane Easter Bahls, Better Safe ...., EnTREPRENEUR, July 2003, at 76 ("CAUTION! Do NOT swallow nails! May cause irritation!"). In broad sense, we can even view our democratic system of government as a feedback mechanism, as past policies shape the norms that voters and those they elect use to decide what to do going forward. 